\title{
Investigating the response of LAI to droughts in southern African vegetation using observations and model-simulations.
}

Shakirudeen Lawal ${ }^{1}$ Stephen Sitch ${ }^{2}$ Danica Lombardozzi ${ }^{3}$ Julia E.M.S. Nabel ${ }^{4}$ HaoWei Wey ${ }^{4}$ Pierre Friedlingstein ${ }^{5}$ Hanqin Tian ${ }^{6}$ Bruce Hewitson ${ }^{1}$

${ }^{1}$ Climate System Analysis Group, Department of Environmental and Geographical Science, University of Cape Town, Cape Town, 7700, South Africa

${ }^{2}$ College of Life and Environmental Sciences, University of Exeter, Exeter EX4 4QE, UK

${ }^{3}$ National Center for Atmospheric Research, Climate and Global Dynamics, Terrestrial Sciences Section, Boulder, CO 80305, USA

${ }^{4}$ Max Planck Institute for Meteorology, Hamburg, Germany

${ }^{5}$ College of Engineering, Mathematics and Physical Sciences, University of Exeter, Exeter EX4 4QF, UK

${ }^{6}$ School of Forestry and Wildlife Sciences, Auburn University, 602 Ducan Drive, Auburn, 
In many regions of the world, frequent and continual dry spells are exacerbating drought conditions, which have severe impacts on vegetation biomes. Vegetation in southern Africa is among the most affected by drought. Here, we assessed the spatiotemporal characteristics of meteorological drought in southern Africa using the Standardized Precipitation Evapotranspiration Index over a 30-year period $(1982$ - 2011). The severity and the effects of droughts on vegetation productiveness were examined at different drought time-scales (1- to 24-month time-scales). In this study, we characterized vegetation using the Leaf Area Index, after evaluating its relationship with the Normalized Difference Vegetation Index. We found that the LAI responds strongly $(r=$ $0.6)$ to drought over the central and south eastern parts of the region, with weaker impacts $(r<0.4)$ over parts of Madagascar, Angola and western parts of South Africa. Furthermore, the latitudinal distribution of LAI responses to drought indicates a similar temporal pattern but different magnitudes across timescales. The results of the study also showed that the seasonal response across different southern African biomes varies in magnitude and occurs mostly at shorter to intermediate timescales. The semi-desert biome strongly correlates $(r=0.95)$ to drought at 6 -month timescale in the MAM (summer) season, while the tropical forest biome shows the weakest response $(r=0.35)$ at 6-month timescale in the DJF (hot and rainy) season. In addition, we found a stronger response (in the year 1983, $r=0.84$ over Namibia and eastern parts of South African) of the LAI to drought during dry years as compared to wet years; and we found different temporal variability in global and regional responses across different biomes.

50 We also examined how well an ensemble of state of the art dynamic global vegetation models (DGVMs) simulate the LAI and its response to drought. The spatial and seasonal response of the LAI to drought is mostly overestimated in the DGVM multi-model ensemble compared to the observations. The correlation coefficient values for the multi-model ensemble are as high as 0.76 (annual) over South Africa, and 0.98 in MAM season over the temperate grassland biome. Furthermore, the DGVM model ensemble shows positive biases (3-month or longer) in the simulation of spatial distribution of drought timescales and overestimate the seasonal distribution timescales. The results of this study may highlight areas to target for further development of DGVMs in order to improve the models' capability in simulating the drought-vegetation relationship.

60 Keywords: Drought intensity; Drought indices; Standardized precipitation evapotranspiration index; DGVMs; southern Africa; Drylands 


\section{Introduction}

Drought can be described as a natural occurrence whereby the natural accessibility of water for a region is beneath the normal state over a long period of time (Xu et al., 2015). Globally, it is considered one of the world's most important climate risks, with significant environmental, social and ecological impacts on different sectors (e.g. agriculture, forestry, hydrology) and human lives (Naumann et al., 2018). Increasing trends in the occurrence and severity of drought in West Africa and Mediterranean have huge impacts on water resources and agriculture (Sultan and Gaetani, 2016). In southern Africa, a region regarded as a climate hotspot because of the projected impacts of climate change on its numerous endemic vegetation, an understanding of these impacts is important for mitigation options in managing future drought events. Therefore, it is important to examine drought impacts on vegetation and evaluate how this is simulated in models.

Drought is a frequent occurrence in southern Africa, and has enormous impacts on vegetation in the region. For instance, drought has resulted in a significant loss of biomes and death of plants (Masih, 2007, Hoffman et al., 2009). It is reported that there are now fewer vegetation coverage in the region compared to what existed between the mid 1990's and 2000's (EOS, 2007). Furthermore, there are projections that by mid-century, southern Africa may lose about one-third of its current vegetation due to increasing exacerbation of drought in the region (Scott, 2005). Drought has also impacted speciation of vegetation thereby causing significant changes to the region's rich biomes, through the lack of formation of new species or even growth of species with underdeveloped morphological and physiological characteristics (Hoffman et al., 2009). Droughtinduced vegetation loss has both ecological and socio-economic consequences on human lives. For instance, studies have shown that food security in the region is threatened due to the continual mortality of vegetation (FAO, 2000; Muller, 2003). Other studies (e.g. Wang, 2010; Khosravi, 2017) have also reported that southern Africa could lose more than $\$ 200$ billion of its GDP from the effects of drought on vegetation. The enormous impacts on vegetation have thus made it imperative to investigate how vegetation might respond to different drought intensities at varying timescales.

95 In order to monitor and quantify drought characteristics, drought indices are used (Wilhite and Glantz, 1985). Drought indices including the SPI (i.e. the standardized precipitation index), standardized water-level index and standardized anomaly index are derived from a single hydrological variable i.e. rainfall (Kwon et al., 2019). Other indices such as the Palmer drought severity index, multivariate standardized drought index and standardized precipitation 100 evapotranspiration index (SPEI) combine two or more variables related to other atmospheric or soil and environmental conditions that may predispose a plant to water stress (Palmer, 1965; Vicente-Serrano et al., 2010; Hao and AghaKouchak, 2013). Among the drought indices, the SPI is the most widely used because of the adjustable timescale and its relatively simple calculation (McKee et al., 1993). It is also recognized as appropriate for use in southern Africa (Hoffman et 105 al., 2009). However, SPI has a significant shortcoming, which is that its computation uses only rainfall without considering the effect of other meteorological variables in the development of drought occurrence (Teuling et al., 2013). In order to address this shortcoming, SPEI was developed for drought monitoring and it is regarded as a more suitable drought index in the region to investigate the spatiotemporal scale of drought (Ujeneza and Abiodun, 2014). SPEI is computed from the difference between potential evapotranspiration (PET) and rainfall (Vicente-Serrano et al., 2010). PET can be computed using different methods such as Hargreaves (HG) and Penman- 
Monteith (PM) method. Although studies (e.g. Vicente-Serrano et al., 2010) have found that PM method captures drought better than HG, other studies (e.g. Lawal et al., 2019) showed this difference is negligible over southern Africa.

115 Many studies have used different indices to quantify observed drought, characterize vegetation, and study drought effects on the productiveness of vegetation across different timescales. Several studies (e.g. Vicente-Serrano et al., 2015; Zhang et al., 2016; Lawal et al., 2019a,b) have shown that the satellite-derived normalized difference vegetation index (NDVI) is one the most important indicators of vegetation health and greenness. These studies applied NDVI in examining drought impacts on vegetation on global vegetation biomes. However, other studies (Gitelson, 2004; Santin-Janin et al., 2009) have argued that while NDVI is a true proxy for vegetation trends, its potential saturation makes it difficult to fully estimate biomass. In addition, because the NDVI parameters are not well calibrated and often missing in models, simulated NDVI can be biased. Due to its high correlation with NDVI, the leaf area index (LAI) is instead used to characterize vegetation conditions (Fan et al., 2007; Zhao et al., 2018). Although the LAI is an important vegetation proxy, it is rarely considered in the estimation of drought impacts on vegetation. Thus, quantifying the response of the LAI to drought over southern Africa is important for understanding the processes that modulate ecosystem services produced by vegetation which are crucial for human survival. (Melillo 2015).

130 Previous studies have also evaluated the performance of coupled climate models in simulating the response of vegetation to drought. For instance, Lawal et al. (2019a) reported that an ensemble of the Community Earth System Model (CESM) showed biases in response simulation of vegetation to drought. This was attributed to the parameterizations of the land component (i.e. Community Land Model, CLM) which poorly simulated observed NDVI. Given the poor replication of 135 vegetation response to drought by a coupled climate model, there is a need to examine land-only models and whether they might better capture drought-vegetation relationship when the atmospheric forcings are derived from observations. The present study used Dynamic Global Vegetation models (DGVMs) to study vegetation response to drought, as little is known on how the LAI response to drought is simulated by DGVMs. The choice of DGVMs is because of their

140 capability in simulating mostly accurate carbon exchange between atmosphere and vegetation ecosystems (Lu et al., 2011).

The aim of this study is to investigate the response of LAI to droughts in southern African vegetation using observations. We also examined how well the responses are represented in model simulations. We used satellite and simulated LAI to quantify vegetation responses to drought. We characterized the spatiotemporal extent of drought and its severity using the SPEI and then assessed the influence of drought using the LAI from satellite data and model simulations.

\section{Data and Methodology}

\subsection{Data}

150 In this study, we used satellite and simulated LAI, and satellite NDVI; gridded observation and reanalysis climate datasets. The gridded observation climate datasets included precipitation, maximum, mean and minimum temperature. These data were gotten from CRU (i.e. the Climate 
Research Unit; Mitchell \& Jones, 2005; Harris et al., 2014). These are global monthly data which have $0.5^{\circ} \times 0.5^{\circ}$ as spatial resolution and spans $1901-2019$ period. Here, we used the CRU data for the period 1982 - 2011 to compute observed drought indices (i.e. SPEI) to characterize the spatiotemporal severity of drought. CRU is a gridded observed datasets, which was used because of its suitable spatial and temporal resolutions. The reanalysis climate data we used are the CRUJRA, which is a combination of CRU and the Japanese Reanalysis data (JRA) (University of East Anglia Climatic Research Unit; Harris, I.C., 2019). It is a 6-hourly, land surface, gridded data with a spatial resolution $0.5^{\circ} \times 0.5^{\circ}$. CRUJRA was used to compute reanalysis drought indices and used for model simulations. Here we aggregated CRUJRA to monthly samples and used the data at the same spatial and temporal resolution as CRU.

For the satellite vegetation indices, first, we used the third generation of NDVI (hereafter, NDVI3g) from the Global Inventory Modelling and Mapping Studies (GIMMS), and spans period from 1981 - 2015, temporal resolution of biweekly and a spatial resolution of about 8km (Pinzon and Tucker, 2014; National Center for Atmospheric Research Climate Data Guide, accessed 2019). Here, we used the data for the period 1982 - 2011. Furthermore, we used the third generation of the GIMMS LAI (LAI3g) which also spans the period 1981 - 2015; has a temporal resolution of biweekly and spatial resolution as GIMMS3g. The LAI data had been processed (at source) using a set of neural networks which were first trained on highest-quality and post-processed MODIS LAI and FPAR products and AVHRR GIMMS NDVI3g data for the overlapping period (2000 to 2009). The trained neural networks were then used to produce the LAI3g and FPAR3g data sets (Mao and Yan, 2019). For the study, LAI3g was also used for the period $1982-2011$.

The simulated monthly LAI data were obtained from eleven Dynamic Global Vegetation Models (DGVMs) which are part of the Trendy-version 7 (Sitch et al., 2008; Le Quéré et al., 2018). These DGVMs are CABLE-POP (Haverd et al., 2018), CLM (Oleson et al., 2013), CLASS-CTEM (Melton and Arora, 2016), DLEM (Tian et a1; 2015), JSBACH (Mauritsen et al., 2018), LPX (Lienert and Joos; 2018), OCN (Zaehle and Friend; 2010), ORCHIDEE (Goll et al., 2017), SURFEX (Joeztjer et al., 2015), JULES (Clark et al; 2011) and VISIT (Kato et al., 2013). LAI from the models have a monthly temporal resolution spanning period from $1901-2017$. We selected these DGVMs because they have been run with similar protocol (S3 simulations) and forcing datasets (i.e. CRUJRA).

\subsection{Methods overview}

\subsubsection{Evaluation of DGVMs and the relationship between NDVI and LAI}

The relationship between NDVI and LAI was evaluated by computing the grid cell spatiotemporal correlation between GIMMS NDVI and GIMMS LAI, as well as spatiotemporal correlation between GIMMS LAI and simulated LAI from individual DGVMs. This was necessary to show whether LAI is an appropriate estimator of NDVI, and how well the models simulate the LAI in the region.

195 The climatology of observed and simulated climatic variables as well as LAI over six major biomes in southern Africa for the period 1982- 2011 were computed. These biomes are semi desert, 
Mediterranean, dry savanna, moist savanna, temperate grassland and tropical forest (Fig. 1; Sinclair \& Beyers, 2015; Lawal et al., 2019a, b).

200

\subsubsection{Description of Drought}

For the present study, we adopted the definition of meteorological drought, "which is described as a period (e.g. a season) during which there is a deficit in the magnitude of precipitation in a particular area compared to the long-term normal (Palmer, 1965; Wilhite \& Glantz, 1985)". Here, we used meteorological drought because it does not make any presumptions about soil characteristics or run-off. In addition, it is acknowledged to be a primary component in the depletion of vegetation productiveness and reduction of biomass (Vicente-Serrano, et al., 2010). Previous studies (Vicente-Serrano et al., 2006; Vicente-Serrano et al., 2013) have also used meteorological drought in the investigation of drought impacts on biomass and vegetation productiveness. It is reported that there is a linkage in the attributes of meteorological and agricultural droughts which culminate in the deficit of soil moisture (Lake, 2011).

\subsubsection{Drought computation and correlation with LAI}

The analyses include calculating drought (i.e. SPEI) using CRU data over a 30-year (1982 - 2011) period for different drought timescales. The drought time-scale can be described as the aggregation of temporal duration (Vicente-Serrano et al., 2010).

A time series of the evolution of drought for the 30-year period was plotted. The present study extends the timeframe for understanding drought impacts through 2011 The study goes to 2011 because there were droughts in the 2005 - 2011 window (Masih et al., 2014). This extension is particularly important considering that southern Africa experiences more frequent droughts with impacts exacerbated by climate change. This information is important for considering adaptation measures and understanding the role of climate change.

The drought index, SPEI, is calculated from the deduction between precipitation $(\mathrm{P})$ and potential evapotranspiration (PET) as shown below;

$$
\mathrm{D}=\mathrm{P}-\mathrm{PET}
$$

where PET is computed from maximum temperature, minimum temperature and mean temperature, using Hargreaves technique (e.g. Vicente-Serrano et al., 2012; Beguera et al., 2014; Stagge et al., 2014). D values are obtained through aggregation over individual time-scales which span 1- to 24-months (i.e. 1-, 3-, 6-, 9-, 12-, 15-, 18-, 21- and 24-month). The time-scales were calculated by including the variable past values effect. For example, a time-scale of 15 -month suggest that input from the preceding 15 months, which includes the present month, was used for calculating SPEI (Beguera et al., 2014). "For the 1-month timescale, only the current month data is used for the calculation. The D values were standardized by assuming a suitable statistical distribution (e.g. gamma, log-logistic). The log-logistic distribution was used to standardize the D values in this study". For more details on the timescale computation, please see Vicente-Serrano et al. (2010); https://rdrr.io/cran/SPEI/man/spei.html. 
We note that the PET in the SPEI was computed using Hargreaves (HG) method rather than Penman-Montieth (PM) because the data (e.g. vapour pressure, maximum and minimum humidity) required for computing PM over southern Africa are sometimes missing or not available at the needed gridded spatial resolutions and timespan. Although PM is considered better in most regions, Lawal et al. (2019a) showed that the variation between the PM and HG is negligible for southern African region. The study only considered observed SPEI_PM which was obtained from https://spei.csic.es/database.html and not modelled SPEI_PM due to the unavailability of simulated data required for its computation. Other studies (e.g. Beguera et al., 2014) have also found that there is an insignificant contrast in the strength of PM and HG for reproducing their divergence on measured variables such vegetation indexes.

We deseasonalized GIMMS LAI by transforming monthly LAI series per pixel to symbolize the standardized deviations from extended mean. This was to make the sequence of LAI commensurate to SPEI (Vicente-Serrano et al., 2013) and eliminate the impact of periodicity on vegetation response. We note that SPEI is intrinsically deseasonalized.

We then computed the correlation per grid-cell between drought index (CRU) and deseasonalized 260 LAI over the 30-year period at the different drought timescales using Pearson correlations. We then compared the spatial distribution of maximum (peak) correlation and the comparable timescales of drought for observed SPEI.

Next, we investigated correlations at each grid cell between the drought (from reanalysis 265 CRUJRA) and an ensemble median of modelled LAI from individual DGVMs. The maximum (maximum) correlations and equivalent time-scales from the complete 1- to 24-month time-scales were mapped for the ensemble median over the 30-year period. We used ensemble median because of its less sensitivity to independent outliers (Reuter et al., 2012). In summary, we calculated model ensemble drought from the indexes median from individual members' drought indexes. The interannual variation of drought impacts on LAI by individual DGVM was also calculated for different timescales.

In simple terms, CRU was used to compute observed drought while CRUJRA was used to calculate modeled drought because it is what was used to force the models. This will allow for easy observation and model comparisons

Similar to Lawal et al., 2019a, we calculated the seasonal mean for four seasons i.e. a) DecemberJanuary-February (DJF); b) March-April-May (MAM); c) June-July-August (JJA); and d) September-October-November (SON) from the correlations of monthly series of drought and LAI.

280 These were computed from correlating monthly series (twelve series per year) per pixel of GIMMS-LAI and each monthly series of 1- to 24-months drought (SPEI) series over the 30-year period with Pearson correlation. The same technique was used for the model ensemble. We calculated the peak correlations and drought timescales of the models over six major biomes in southern Africa namely (Fig. 1) - Temperate grassland, Tropical forest, Moist Savanna, Dry 285 Savanna, Semi-desert and Mediterranean vegetation. These regions were selected because of their relative importance and they are most affected by drought. 
Finally, the impacts of extreme events (wet and dry years) at different time periods were compared; and the comparison of global and regional responses to drought across biomes for the period 1982

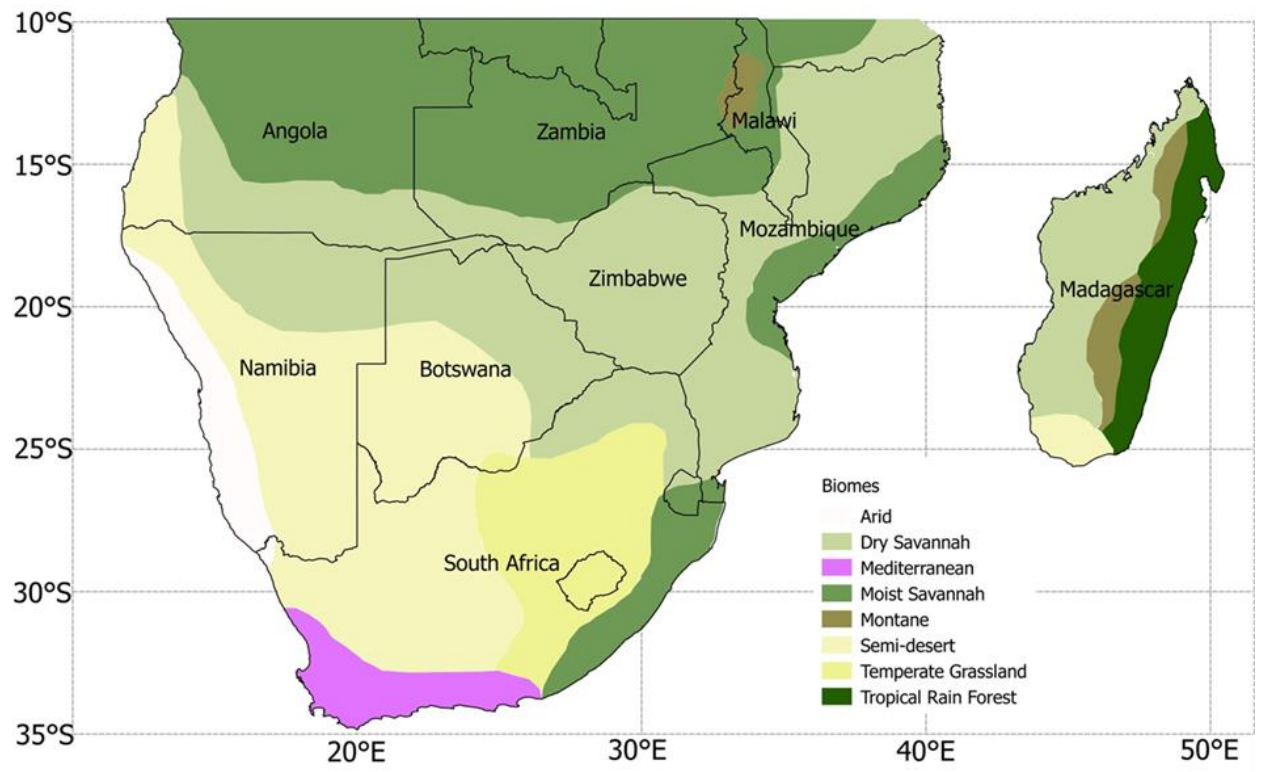

Figure 1. Major vegetation biomes in southern Africa (adapted from UNEP, 2008, Sinclair \& Beyers, 2015 and Lawal et al., 2019a,b). The black contours indicate political boundaries.

\section{Results}

\subsection{Grid cell correlations between NDVI and LAI}

Figure 2 illustrates the relationships between NDVI and LAI for observations, as well as the comparison between observed and model LAI. There is a strong linear relationship between observed NDVI and LAI (Fig. 2a). It can be seen that the correlation (0.94) is high between both variables and the standard deviation is low (0.005). From the figure, there is a log-like shape, where NDVI grows faster when LAI is low $(<0.2)$ and becomes saturated when LAI goes higher $(>0.3)$. A linear regression of the data shows a slope of 2.15. The low standard deviation indicates that the values from the two indices are close and a standard lower deviation. Although there is a good agreement between observed NDVI and LAI, the 1:1 line shows that the datasets are not exactly equal to each other.

310 Furthermore, there is good agreement between observations and the simulated LAI (Fig. 2). JULES and has the highest correlation (0.97) with observation (Fig. 21). CLM has the weakest (0.73) correlation with the observations (Fig. 2c). DLEM and LPX have the same correlation coefficient value of 0.87 with observation (Fig. $2 \mathrm{e}, 2 \mathrm{~g}$ ). The positive relationships between simulated and observed LAI indicate a general applicability in investigating the model's 
performance of vegetation response to drought. It also shows that the correlation is strong enough to compare how the LAI reacts to drought in the ensemble. An aggregation of observation along the gradient of simulated LAI shows that most of the models have similar slopes with observation.
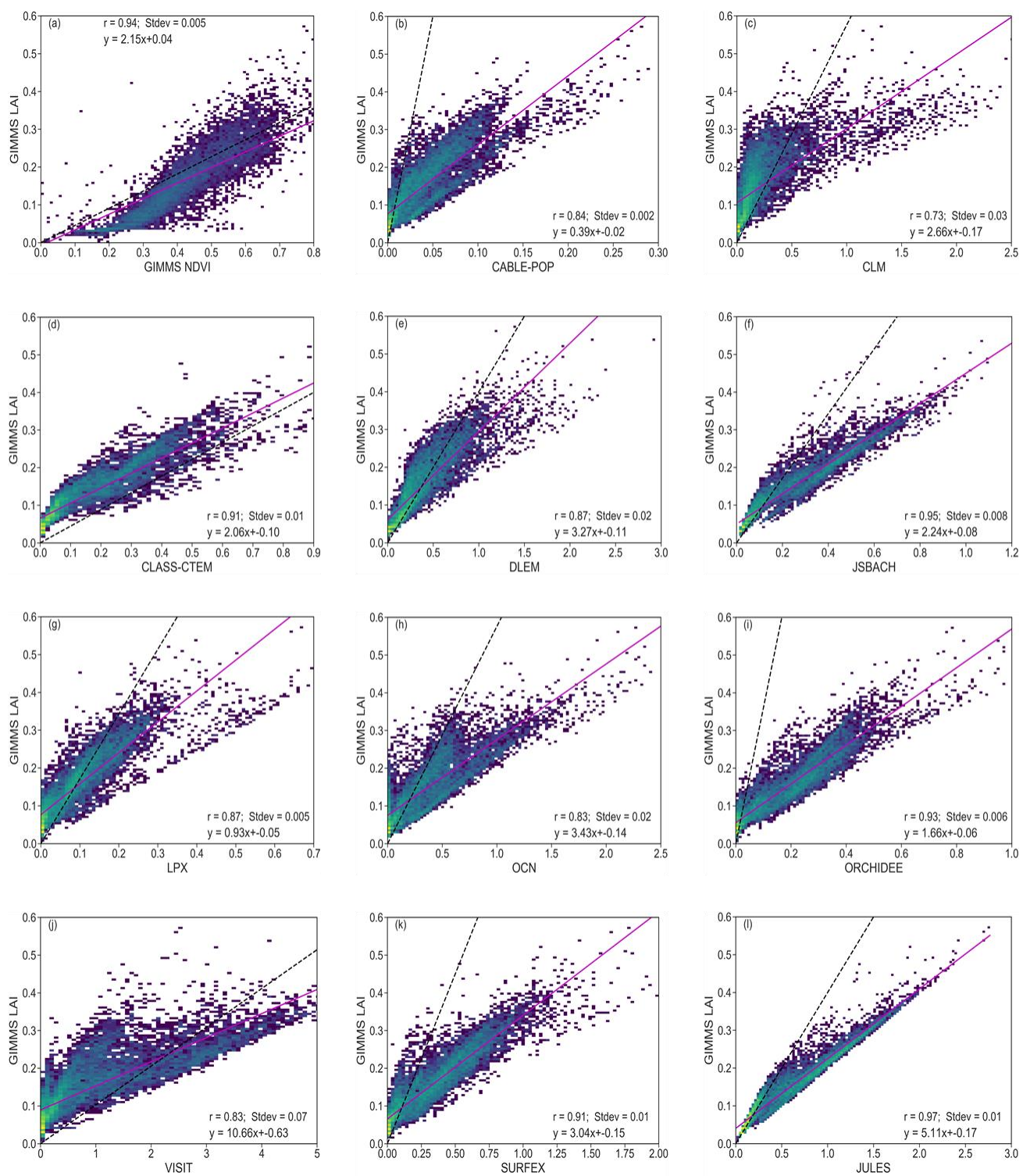

Figure 2. Scatterplots of correlations between vegetation indices (observation and model) for the period 1982 - 2011 over southern Africa. Inset values indicate the correlation coefficient (r) and standard deviation (Stdev). The color represents each grid cell. The pink solid line is the linear regression, while the dashed black line shows 1:1 line. The unequal $\mathrm{x}$-axes is to visualize the detailed data for the models. 


\subsection{Climatology of observed and, simulated climate variables and LAI}

This section compares the seasonal cycle of observation (CRU) and reanalysis (CRUJRA) climate variables; as well as observed and simulated LAI from GIMMS LAI and TRENDY models, respectively. Precipitation and temperature variables are seasonally variable and their climatologies are mostly similar. For example, precipitation is higher in MAM and DJF seasons over many of the biomes except in Mediterranean vegetation where precipitation is higher in JJA season. (Fig. 3a, 3b, 3e, 3i, 3k). The wettest month occurs over TF (i.e. tropical forest biome) where the precipitation is about $350 \mathrm{~mm}$. Conversely, during the dry season (JJA), there is little rainfall in the biome, although, it experiences some precipitation June and July months. Over the Mediterranean vegetation (Fig. 3g), a winter (JJA) rainfall region, rainfall variability is lower and is mostly dry in the DJF and SON. Similarly, the highest minimum and maximum temperature in the region is observed in the DJF season, where the highest temperature value exceeds $30^{\circ} \mathrm{C}$. Over the tropical forest biome, although the distribution pattern of precipitation and temperature are similar for most months, they differ during June and July months. The pattern of precipitation and temperature distribution generally differ over the Mediterranean vegetation.

There are not strong patterns of seasonality in LAI, with maximum observed LAI values less than 4 in all biomes. The models well reproduce the climatology of LAI over the southern African biomes with a few exceptions (Fig. 3b, 3d 3f, 3h, 3j, 31). For instance, the models simulate the drop in LAI over the semi desert, temperate grassland, tropical forest, dry savanna and moist savanna biomes in JJA season. The highest increase in observed LAI occurs over the tropical forest in April, although the models simulate a decrease in LAI over tropical forest during this time. On the other hand, lowest amount (less than 0.1) of LAI is observed in September and this occurs over the semi-desert biome. Observations typically fall within the range of the model ensemble. In addition, the distribution patterns of simulated LAI is similar to observation in most biomes except in the Mediterranean and tropical forest biomes. The LAI pattern also follows that of the climatic variables although the former lag behind. 

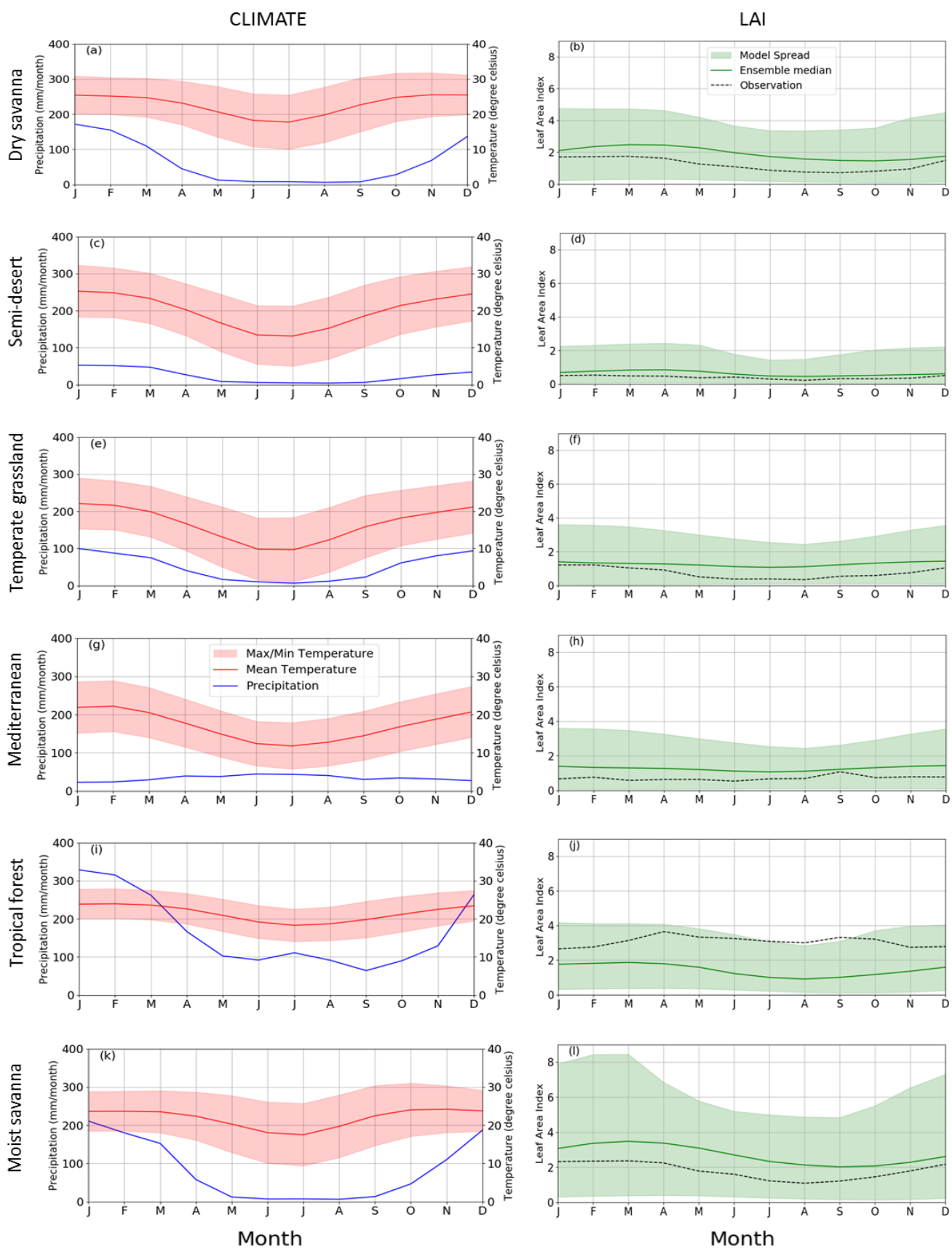

Figure 3. Annual cycle of observed climate variables (precipitation, $\mathrm{mm} / \mathrm{month}$; maximum, minimum and mean temperature, ${ }^{\circ} \mathrm{C}$ ) and LAI for observation and multi-model mean (TRENDY) across six southern African biomes over for the period $1982-2011$. The annual cycle of the LAI for individual models are shown in Figure S5. 


\subsection{The evolution of drought in southern Africa}

Figure 4 shows the evolution of observed SPEI in southern Africa between 1982 and 2011. Here, drought indices from CRUJRA are not included because preliminary investigation showed close magnitudes for drought indices computed from CRU and CRUJRA. We note that CRU was used to calculate SPEI for observation while simulated SPEI was computed with CRUJRA.

There is inter-annual, seasonal and decadal variability of the drought indices during dry and wet conditions over southern Africa. Although 1-, 3- and 6-month SPEI indicate no trend in wet or dry spells, they show the intensity of drought event for the 30-year period (Fig. 4a, 4b, 4c). The highest magnitude of drought is captured by 1-month SPEI while the lowest is shown in 21-month SPEI.

The severity of drought intensity is similar for all SPEI.

We note that the increasing trend in SPEI (9- to 24-month) does not imply that drought stress has decreased over time. There is need for more robust analysis to make such a conclusion.
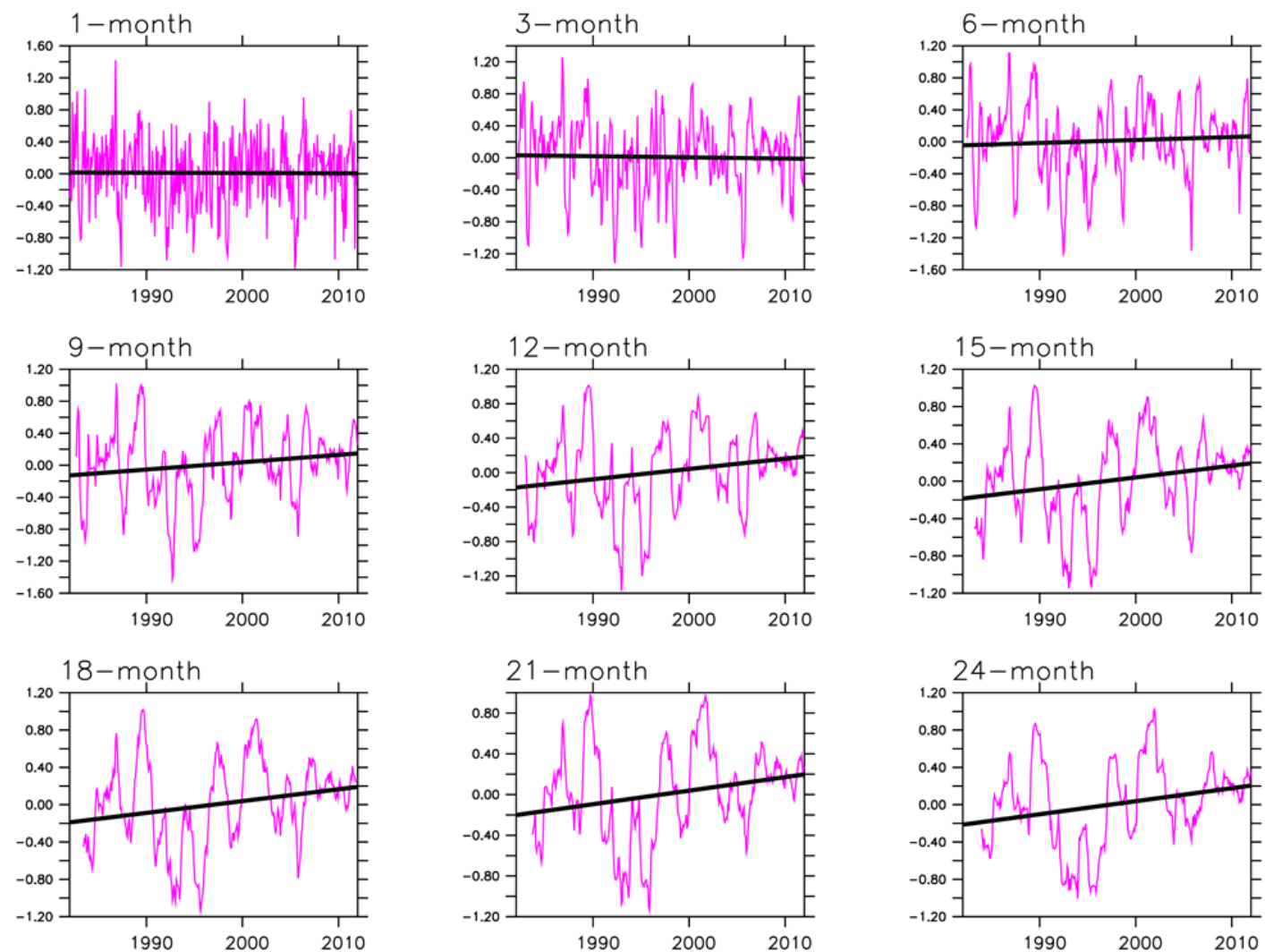

Figure 4. Evolution of SPEI in southern Africa for the period 1982 - 2011. The trend is significant at $90 \%$ confidence interval for all timescales. 


\subsection{Spatial distribution of LAI response to drought and the timescales}

Figure 5 presents the spatial distribution of the peak correlation between the SPEI and the LAI, and the timescales at which the correlation occurs. This is to show the magnitude of response of LAI to drought in southern Africa, and the length of the period for the response.

Observations show that southern African LAI can respond fairly strongly to droughts (peak correlation magnitudes of between 0.4 and 0.6), though the response is much weaker (coefficient of less 0.4) in eastern Madagascar, Angola and parts of South Africa (Fig. 5a). The TRENDY multi model median generally overestimate the observed magnitude of the LAI to drought response (Fig. 5c). Peak correlations for the models seem to be much stronger - in the 0.6-0.8 range for most of the regions. In addition, over the arid areas of Namibia, models simulate a LAI while observations depict no measurable LAI, indicating that models simulate the LAI in areas where observations show no measurable LAI.

The multi model median have a drought timescale that is mostly longer than the observed (Fig. 5b, d). For instance, drought response of simulated LAI occurs mostly over a longer time period (6-, 9-month timescale) than in the observation over eastern Madagascar. Over southern areas of Madagascar and central Zambia, the multi model median overestimates the drought timescale. Over central areas of South Africa and Mozambique, simulated LAI responds at intermediate (9month) timescales. However, similar drought timescales for the observation and the model ensemble median are shown in parts of Angola. 

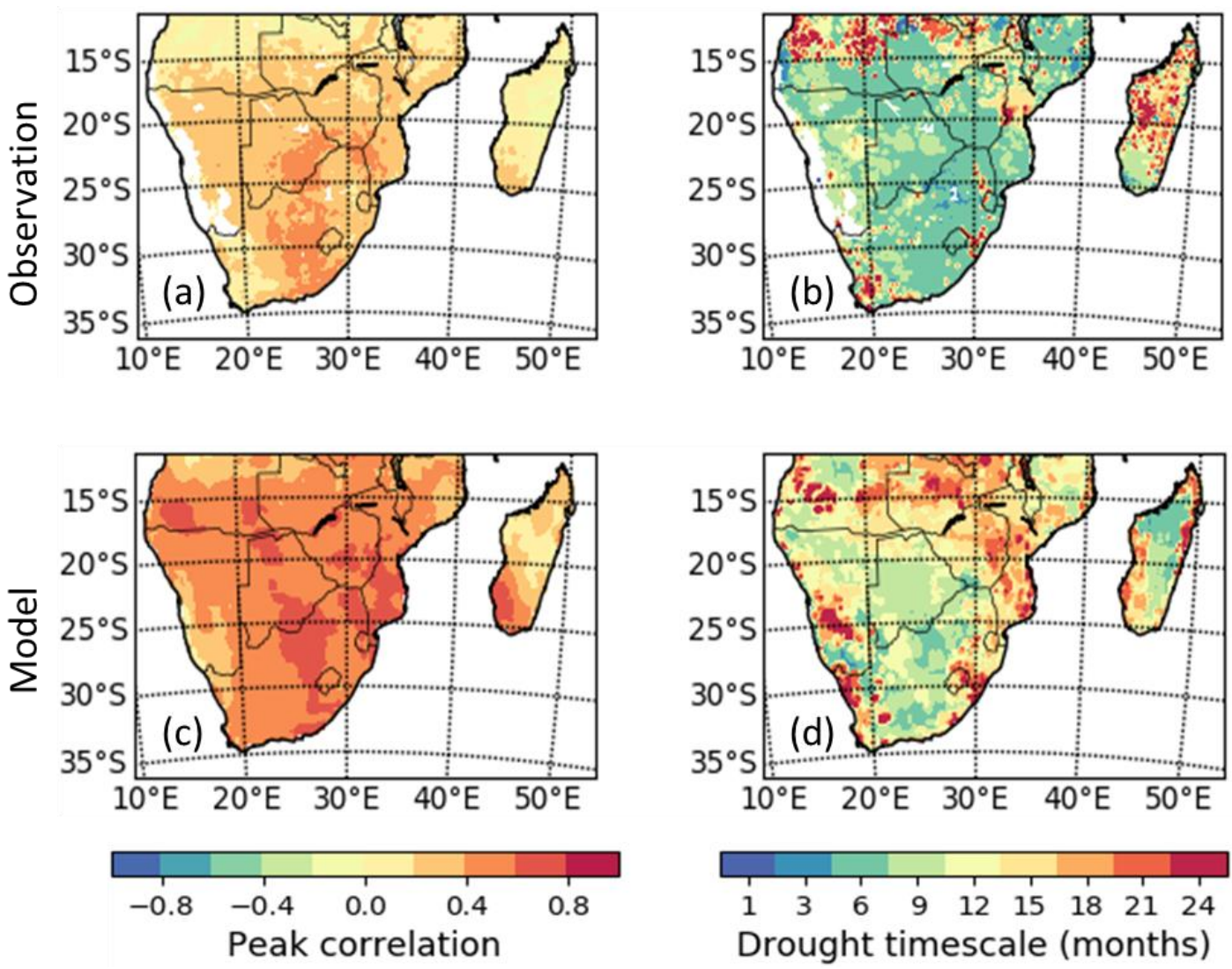

Figure 5. Spatial distribution of peak correlation between drought (SPEI) and LAI over the region of southern Africa in the observation and in the model ensemble median; for the period 1982 2011. Panels (a) and (c) show the peak correlation per pixel, which is independent of the timescale and the month of the year. Panels (b) and (d) indicate the timescales at which the peak correlation between SPEI and LAI is found. Areas with no significant correlation are white.

\subsection{Latitudinal distributions of LAI response to drought and the timescales}

The present study investigated and discussed the implications of drought different vegetation/biome types across latitudes in the region. While the pattern of the latitudinal distribution of the LAI response to drought is identical across different timescales, the magnitudies generally differ (Fig. 6). The response is much weaker (less than 0.15) for the 1-month timescale than for other timescales. The strongest response is observed at 6-month timescales between latitudes 25 and $30^{\circ}$. The model ensemble mean generally agrees with the pattern of the observed LAI-SPEI correlations across all the timescales. However, the magnitudes differ from the observation. Modeled correlation is stronger than observations for the longer (6-month or more) 
425 timescales. Furthermore, there is an offset between observation and model mean which is consistent across most of the timescales, perhaps due to strong memory of the some of the models.
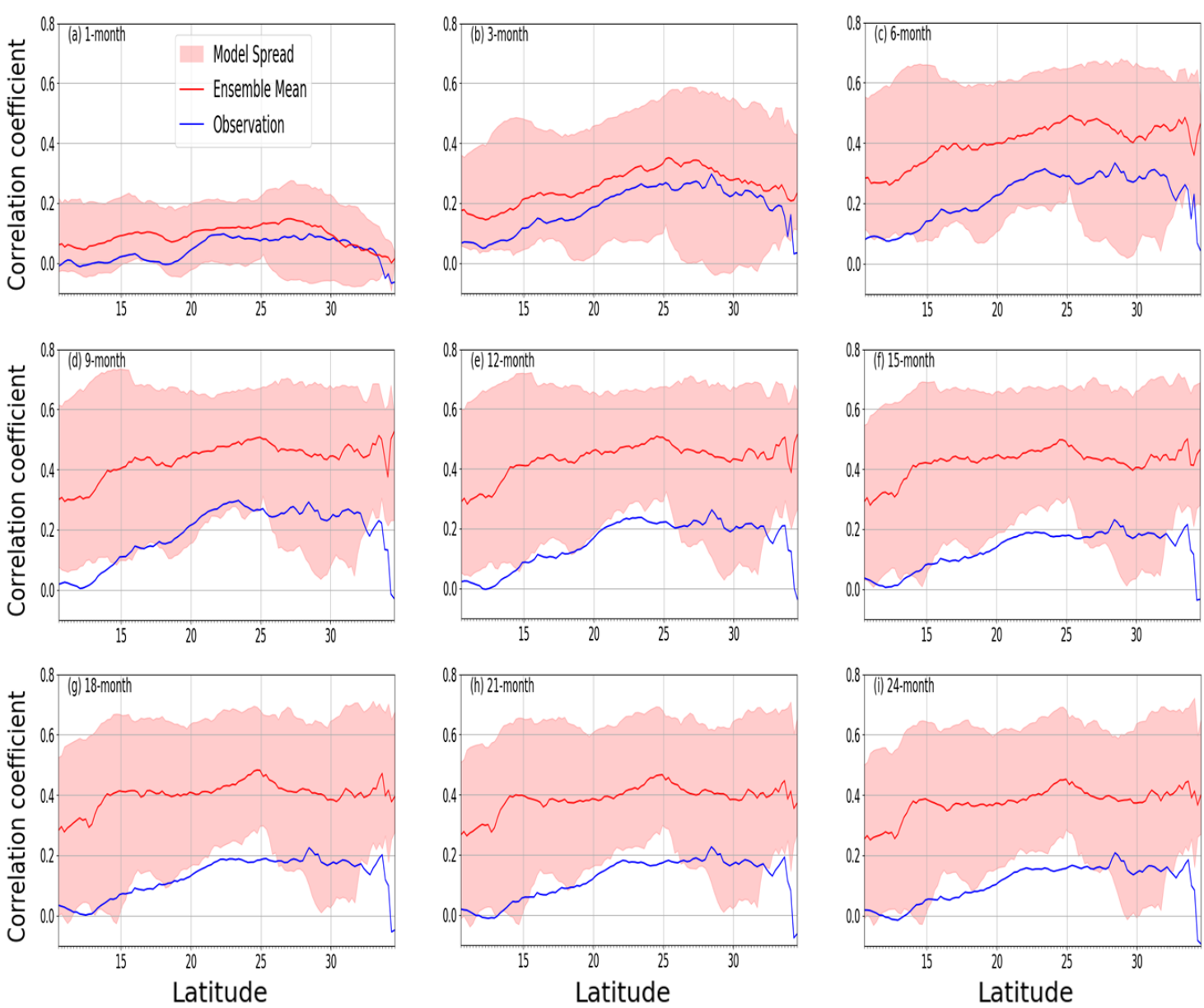

Figure 6. Mean correlation (observed and multi-model ensemble) of annual LAI and SPEI for 1982 - 2011 across latitudes over southern Africa for 1- to 24-month timescales.

\subsection{Response of LAI to droughts across seasons}

Observations show similar correlations between LAI and drought across all seasons in the biomes

(Fig.7). For the dry savanna which is one of the most climate-impacted biomes in the region, LAI response to drought is strong and as high as 0.8 in MAM season and it occurs at 12-month timescale. The correlations between drought and LAI are also very strong in other seasons over the same biome and occur at 6- and 12-month drought timescale, except over the Mediterranean vegetation where the response occurs at 18-month in DJF season. Similarly, the peak correlations 
440 between drought and LAI are strong across the other biomes. With exception of the tropical forest biome, the drought timescale is at longer time periods (> 6-months).

The model ensemble generally overestimates the magnitude of correlations across the biomes in the different seasons. Whilst the correlation magnitude remains mostly larger than the observed, nonetheless, models simulate closer correlation with observation in some biomes and seasons. For instance, over Mediterranean vegetation, models simulate fairly good response of LAI to drought in all seasons. Furthermore, in nearly all other biomes, the ensemble spread overlaps with the observations. In addition, simulations mostly overestimate drought timescale. 

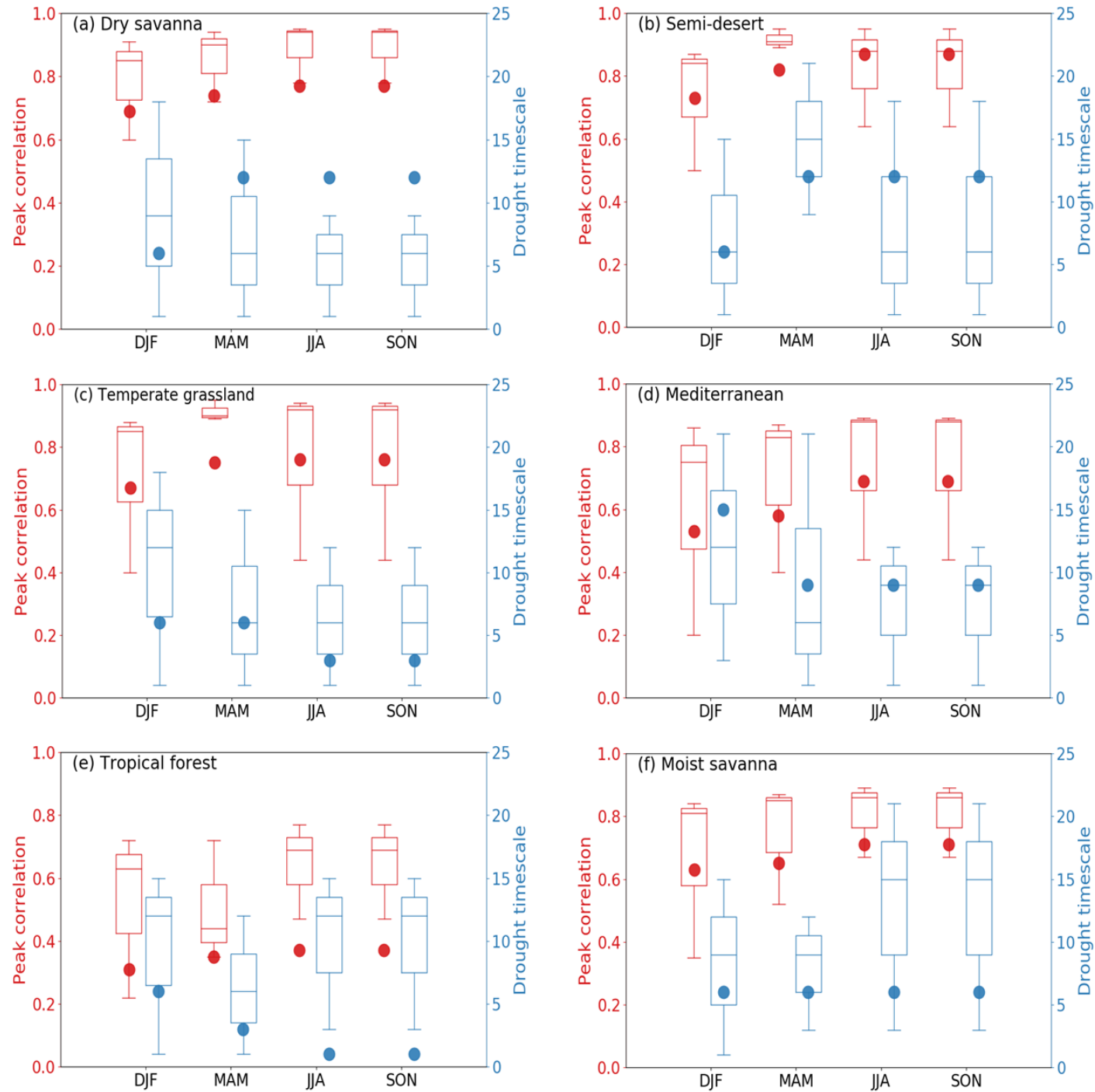

\section{- Correlation (observed) \\ Correlation (model) \\ - Drought timescale (observed) \\ Drought timescale (model)}

475 Figure 7. Seasonal correlations of drought (SPEI) and LAI across six southern African biomes. The values on the left axis show the peak correlation in observation and TRENDY models. The values on the right axis indicate the correlation drought timescale. 


\subsection{Inter-annual variation of model simulation of drought impacts on LAI}

Table 1 shows correlations between observed mean SPEI and LAI for the period 1982 and 2011 as well simulations by individual DGVM across different timescales. Unlike Fig. 5 which shows the peak correlations, the table shows the mean correlation for the 30-year period.

There is variation in the inter-annual simulation of LAI response to drought across different timescales by individual models. For instance, on the 1-month timescale, JULES simulates the least correlation value while JSBACH shows the highest correlation value. Furthermore, JSBACH simulates the highest correlation value for most of the timescales while CLM simulates the least correlation values for most (3-, 9-, 12-, 15- and 18-month) of the timescales.

Table 1. Model simulation of mean SPEI and LAI correlations between 1982 and 2011.* indicates the model with the lowest mean correlation.

\begin{tabular}{llllllllllllll}
\hline Correl. & $\begin{array}{l}\text { GIMMS } \\
\text { LAI }\end{array}$ & $\begin{array}{l}\text { CABLE- } \\
\text { POP }\end{array}$ & CLM & $\begin{array}{l}\text { CLASS- } \\
\text { CTEM }\end{array}$ & DLEM & JSBACH & LPX & OCN & ORCHIDEE & SURFEX & JULES & VISIT \\
\hline 1-month & 0.0066 & 0.1017 & 0.1188 & 0.1266 & 0.085 & 0.1388 & 0.0842 & 0.0579 & 0.0884 & 0.1094 & $0.027^{*}$ & 0.086 & \\
3-month & 0.0775 & 0.3084 & $0.0187^{*}$ & 0.29 & 0.2499 & 0.4165 & 0.2403 & 0.1644 & 0.266 & 0.2791 & 0.1434 & 0.1108 \\
6-month & 0.091 & 0.3474 & 0.1806 & 0.3562 & 0.3305 & 0.5404 & 0.2386 & 0.3377 & 0.3733 & 0.3759 & 0.2429 & $0.1703 *$ \\
9-month & 0.0832 & 0.333 & $0.2034^{*}$ & 0.3496 & 0.3437 & 0.5734 & 0.2505 & 0.4055 & 0.39 & 0.3994 & 0.3189 & 0.23 \\
12-month & 0.0813 & 0.3053 & $0.2155^{*}$ & 0.3231 & 0.3229 & 0.5398 & 0.304 & 0.4109 & 0.4054 & 0.3911 & 0.3663 & 0.2892 \\
15-month & 0.0642 & 0.2773 & $0.2161^{*}$ & 0.2912 & 0.2846 & 0.4925 & 0.3208 & 0.4106 & 0.4132 & 0.3547 & 0.3623 & 0.3198 \\
18-month & 0.0452 & 0.2534 & $0.2349 *$ & 0.276 & 0.2381 & 0.4599 & 0.2405 & 0.3998 & 0.4109 & 0.3289 & 0.3586 & 0.3472 \\
21-month & 0.0406 & 0.239 & 0.2402 & 0.27 & 0.2119 & 0.4334 & $0.1569 *$ & 0.3739 & 0.3962 & 0.2955 & 0.3621 & 0.3501 \\
24-month & 0.0409 & 0.2302 & 0.2355 & 0.2668 & 0.2186 & 0.4696 & $0.2064 *$ & 0.3528 & 0.3777 & 0.2682 & 0.3617 & 0.327 & \\
\hline
\end{tabular}




\subsection{Impacts of extreme events on LAI}

The impact of extreme events on LAI is shown in Fig. 8. Here, extreme events are the wet years i.e. the periods with precipitation higher than normal; and the dry years which include the periods of very high dry spells.

The magnitudes of response of LAI are generally stronger during the dry years than in wet years (Fig. 8). The distribution pattern of the magnitude of response however, varies across the region. With the exception of the year 2010, the strongest drought response is observed in parts of Namibia, Botswana, Tanzania and South Africa. During the 2010 wet year period, the response is weaker in most parts except northern part of Madagascar and southwestern part of South Africa (Figure 8F).

(A) 1983

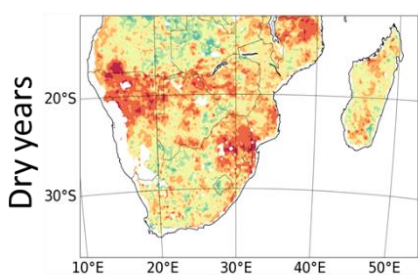

(D) 2000

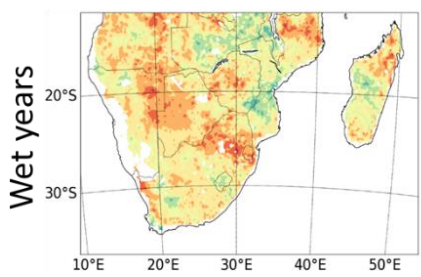

(B) 1984



(E) 2010

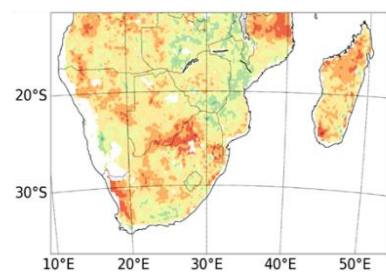

(C) 1991

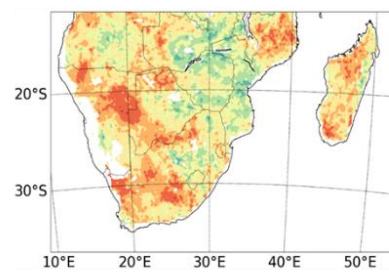

(F) 2011

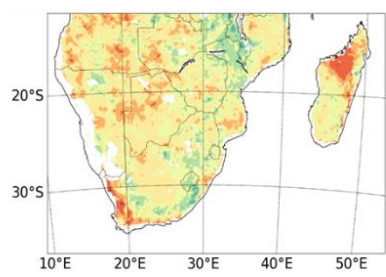

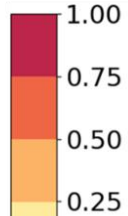

0.25

0.00

$-0.25$

$-0.50$

$-0.75$

$-1.00$

Figure 8. Spatial correlations of observed LAI response during extreme wet and dry years. For (A) - (C) changes were calculated as a difference between the wet year and the 30-year mean and for (D) $-(\mathrm{F})$ between the dry year and the 30-year mean. White are areas with no correlation.

\subsection{Comparison of global and regional distribution of LAI response to droughts $(1982-2011)$}

510 There is variability in the global and regional temporal distribution of LAI response to drought (at 12-month timescale) when global vegetation biomes are split into regional biomes (Fig. 9). The map of the global biomes is shown in Fig. S1 in the supplementary material. The observed global response, indicates a decreasing trend of LAI while the model mean shows an increasing estimate.

515 The semi-desert biome dominates the LAI response as higher drought-vegetation correlations are observed (Figures 9G-I). Over the biome, there is more marked interannual variability which makes the biome an important player in global carbon cycling (Poulter et al., 2014). The response 
over the semi-desert in southern Africa is however weaker in comparison to the other semi-desert biomes.

The response over the Mediterranean vegetation in Australia is stronger than the Mediterranean vegetation over the rest of inland southern Africa. Over the biome, model simulates closer magnitudes in the latter than over Australia (Figures 9B and 9C).

Over the tropical forest biomes, there is a weaker response in Central Africa compared to Southern Africa and South America; the model simulates a closest response magnitude in South America (Figures 9D-F).
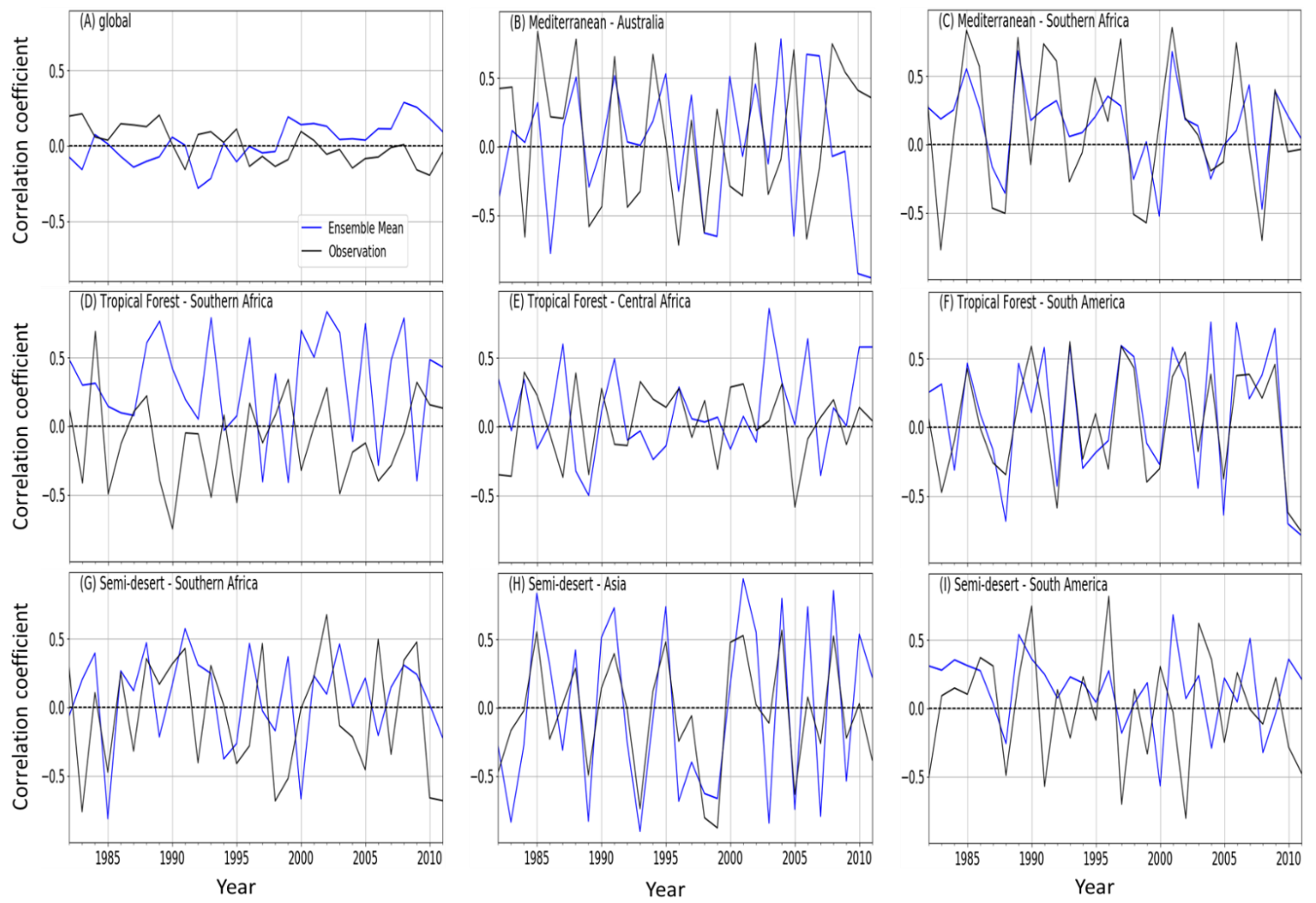

530 Figure 9. Correlations between SPEI (12-month timescale) and ensemble mean of LAI from TRENDY (blue line), GIMMS LAI (black line) for (A) Global (B) Mediterranean vegetation over Australia (C) Mediterranean vegetation over southern Africa (D) Tropical Forest over southern Africa (E) Tropical Forest over Central Africa (F) Tropical Forest over South America (G) Semidesert biome over southern Africa (H) Semi-desert over Asia and (I) Semi-desert over South America. 


\section{Discussion}

\subsection{Relationship of LAI to phenological changes}

LAI is a variable that is needed for global modelling of biogeochemistry, climate, ecology and hydrology and different primary production models (e.g., Running \& Coughlan, 1988; Sellers et al., 1996; Bonan, 1998). In view of the need to run biogeochemical models at regional and global scales, accurate LAI data at moderate - high resolutions is crucial (Wang et al., 2004). The relationship between NDVI and LAI is applied as a support algorithm in MODIS LAI. Thus, from the viewpoint of availability of data, retrieving LAI from analyzing NDVI-LAI relationship remain the main perspective for high temporal resolution in regional and global-wide studies (Wang et al., 2004).

LAI showed a linear relationship with NDVI. This suggests that the NDVI is associated with the phenological changes of plants, the parts of surface cover class which contribute to the general reflectance as well as the variations in the angle of solar zenith (Wang et al., 2004). Studies (e.g. Myoung et al., 2013) have however, found that the relationship between NDVI and LAI varies intra- and inter-annually. For instance, while the relationship is strong during periods of leaf production and senescence, no relationship is observed during the period of leaf constant due to NDVI saturation above certain LAI values (Xue and $\mathrm{Su}, 2017$ ). Other studies have also shown that the relationship between the two vegetation indices differs temporally and seasonally over deciduous forests, which are sometimes not accounted for in models that test their relationship (Wang et al., 2004).

Our study analyzed the relationship between NDVI and LAI using spatiotemporal correlation technique (See Fig. 2a). However, we note that using a single approach to evaluate the relationship between both vegetation indices may be insufficient. This is due to the fact that deviations could be introduced in the estimations of LAI and thus, estimations of carbon fluxes and balances (Wang et al., 2004). Studies have suggested that various relationships should be used, for instance, in the case of deciduous forest, the three stages of phenology such as leaf constant, leaf senescence and leaf production, could be explored (Din et al., 2017; Junges et al., 2017). It has also been proposed that, for the inter-annual variation, the relative NDVI should be used to evaluate inter-annual variation in the relationship at different phenological stages (Hou et al., 2015). Furthermore, other studies have also recommended using correlation based on coefficients of regression and environmental factors such as water availability, temperature, and soil factors (Glen et al., 2008). However, further study is required to test the viability of this approach. In addition, another method that has been proposed is the coupling of various spectral vegetation indices from different temporal scales into the regression analysis as this could add significant improvement over regressions based only on one vegetation index (Cohen et al., 2003).

Although the present study found a strong linear relationship between the NDVI and LAI in southern Africa, other studies (Potithep et al., 2010; Pedro et al., 2019) have shown the two indices

575 are not always directly proportional. For example, both indices do not exhibit the same relationships over different eco-regions such as the Evergreen Broadleaf Forest, Deciduous Needleleaf Forest. Furthermore, another study (Fan et al., 2009; Tian et al., 2016) found that the 
LAI may be better indicator of plant biomass and health because of the saturation associated with the NDVI, particularly in drylands. This makes the LAI more applicable in monitoring vegetation response to drought. Evaluating how the LAI differs from the NDVI over different biomes (such as dry savanna, tropical forest, etc), with regards to temporal difference is shown in Fig. S6.

\subsection{The importance of sub-monthly data in drought computation and monitoring}

585 The data used to evaluate drought indices is CRUJRA. While CRUJRA is based on CRU, it is different because it is a reanalysis and has 6-hourly temporal resolution. Additionally, CRUJRA is the data used to force the DGVMs, so the drought indices are being calculated based on the same data the models use for their simulations. JRA is reanalysis but the combined product uses the submonthly information from JRA but is constrained to the monthly CRU observation. Please see Fig.

$590 \mathrm{~S} 7$ for the spatial comparisons of the data. It is useful to use data with shorter times because the study focuses on an evaluation of drought impact, which is sensitive to timescale. In drylands, for instance, the uncertainties associated with monthly data in drought monitoring are reduced when sub-monthly data are used (Mukherjee et al., 2018).

\subsection{Annual cycle of climate and vegetation in southern Africa}

Climatologies of meteorological variables show that precipitation drops in JJA and SON seasons over the biomes except over Mediterranean vegetation. The dry condition that is experienced during these seasons could be attributed to the subtropical high pressure system which suppresses rainfall by shifting the ITCZ (the Inter-Tropical Convergence Zone) away from these regions (Naik and Abiodun, 2016).

Observations also show low LAI over some parts of southern Africa (please see Figure S2). The weak gradient in some parts of the region may be due to low winter rains produced by the frontal system which is not sufficient enough for growth of expanse vegetation (Lange et al., 1999). The aridification of the western part of southern Africa may be attributed to the influence of cold sea surface temperature (SSTs) of the Namibian Upwelling system along the Namibian coasts (Ward et al., 1983). The aridification does not only result in cessation of river discharge but also sediments that would have favored the growth of drier vegetation (Dupont, 2006).

\subsection{LAI response to drought in observation}

Drought is becoming frequent and more intense in southern Africa (Masih et al., 2014). The 610 frequent and stronger dry spells observed in Fig. 4 could be attributed to climate change. The severity and longer durations of drought have enormous impacts on the already endangered vegetation biomes in the region (Hoffman et al., 2009). The results show that drought impacts on vegetation occur across the different seasons in the region. The seasonal difference in the response of vegetation to drought across biomes is influenced by numerous factors such as vegetation adaptive capacity and resilience, reproduction process, growth stage among others (Zeppel et al., 2014; Corlett, 2016). For instance, over the tropical forest biome, drought has the least impact on vegetation in the region, which could be because of the deeper rooting system of the vegetation which allows them access to soil at the deeper water table (El-Vilaly et al., 2017). It is reported 
that major drivers of vegetation resilience and productivity are precipitation and temperature which control the evapo-transpirative rate (Allen et al., 2010). It is worth noting that vegetation in southern Africa will be severely impacted if the trends continue in the same trajectory. For instance, the regions where there is a strong vegetation response to drought are experiencing wood encroachment and thus, will likely worsen based on the current trajectory of drought occurrence.

We note that the performance of drought indices is not only limited by the variables used in their computation but also by biomes and location where they are used (Xu et al., 2015). For example, SPI which is calculated using simple methods and has adaptable timescales performs better than SPEI in arid regions (Bengueria et al., 2014). However, SPEI which requires more variables for its computation captures drought better in relatively humid zones (Bengueria et al., 2014). SPEI is however limited by the potential evapotranspiration (PET) because of its sensitivity to the variable 630 (Xu et al., 2015).

The vegetation situated at the borders of Botswana-Namibia and Mozambique-Zambia respond to droughts at an intermediate timescale (i.e. 9-month). The types of vegetation inhabiting these regions, which are well adapted to water shortage because of their physiological and morphological characteristics, takes prolonged period to respond to drought and thus, do not easily shows symptoms of water strain (Vicente-Serrano et al., 2013). The activities through which vegetation minimize water loss include reduction in photosynthesis, reduced canopy cover (Schwinning \& Sala, 2004). The capacity for vegetation to store water is one adaptation for low water ecosystems, as is reduced daytime stomatal conductance and CAM photosynthesis. The disparity in the timescales spatial distribution in models from obsevation might be because the parameters are represented and estimated in the models (Murray et al., 2012). In addition, the models are not similar in their drought timescales simulations.

The varying response of the tropical forests in different regions may be because of the interplay of precipitation and temperature at different longitudes. Ahlstrom et al (2015) showed that temperature is particularly a strong factor in the response of this vegetation. Wang et al (2018)

645 also reported that soil moisture variations play a key role in the magnitude of vegetation response. The weak response of LAI to drought over Madagascar and Angola may be attributed to the fact that the vegetation in these regions is able to store water for a long time which it uses during deficit (Chapotin et al., 2006). It may also be because rainfall is not the main regulatory component in the growth of vegetation in these regions (Fuller and Prince, 1996). In regions such as Botswana and

650 Namibia, vegetation is highly dependent on water availability for their ecosystem functions (Anyamba et al., 2003). Please see Fig. S3 in the supplementary material for observed correlations at different timescales.

The seasonal response of LAI to drought varies and this could be attributed to many factors. For instance, the sensitivity of the semi-desert to water shortage makes them show quick response to drought (New, 2015). The response is particularly stronger in the MAM season because it is during this period that fruit, and develops leaves and biomass are produced by vegetation (Zeppel et al., 2014). Critical water requirements by vegetation for these developmental activities in the MAM season is the reason for the vegetation respond to droughts at a short timescale (Zeppel et al., 2014). The strongest vegetation response (a correlation of about 0.92) is observed over the semi desert biome (which is in the semi-arid environment) in the JJA season. This is a region with 
vegetation which heavily depend on water for all their ecosystems functioning without which they would not survive (New, 2015). The drought response of tropical forest is weaker compared to all other biomes. Over the tropical forest biome, the fairly subtle drought response may be because the biome can be tolerant to drought, have stronger robust capacity and is therefore, not extremely impacted by droughts as are the other biomes (Gilgen et al., 2005; Corlett, 2016).

The different response by the global biomes in different geographical locations may be because of climate variations and the sensitivity of LAI to climate variations (Ahlstrom et al., 2015). The dominance of LAI response to drought over the semi-desert biome could be attributed to the global bush encroachment and is in consonance with the increasing greenness (Donohue et al., 2009; Fensholt et al., 2012; Andela et al., 2013). Studies (Cai et al., 2014; Trenberth et al., 2014; Dai et al., 2013; Wang et al., 2014; Ahlstrom et al., 2015) have also found that increased and frequent ENSO events due to climate change have not only led to the expansion of LAI but could increase the water demand by semi-desert vegetation. This comparison is particularly important because until now, there has been little or no study on this.

\subsection{How well drought and LAI response is represented in DGVM simulations}

680 The observed LAI is simulated within the models and calculated by GIMMS based on Mao and Yan, 2019. Lu et al., 2011 found that DGVMs perform better against observations than Earth system models (ESM) because they use observationally-derived climate and can include more complex representations of vegetation processes. The ESM is a coupled model simulating its own climate, while the individual DGVMS models used in the present study are standalone, i.e. are 685 applied with observational based meteorological forcing, and thus we remove one uncertainty. Since offline studies target the DGVM itself, removing one possible issue (incorrect climate drivers), it became imperative to use DGVM to study drought impacts.

DGVMs simulate the vegetation characteristics and impacts of climate on them. The validation of DGVM simulations of variables such as LAI is quite difficult. This is because of the unavailability of data on large spatiotemporal scale for the different vegetation classes (Potter and Klosster, 1998). Studies (e.g. Potter and Klooster, 1997) have also shown that errors present in the prediction of plant functional types (PFTs) tend to spread to biomass prediction in the model, thus possibly biasing estimates of carbon stored in terrestrial ecosystems. Nevertheless, the DGVMs used in this 695 study simulate the spatial patterns of vegetation distribution though with a magnitude bias as shown in Fig. S2 in the supplementary material.

TRENDY models mostly simulate the temporal patterns of global and regional distributions of LAI response to drought. The biases shown by the models have been attributed to the fact that the models do not factor land use changes (Ahlstrom et al., 2015). This is evident in the simulation of LAI (please see Fig. S2).

The models' weaker simultion might also be because some of the DGVMs do not well reproduce the LAI magnitude. The negligible difference in the spatial distributions of SPEI of the models could be due to fact that the model PET does not play a strong role in drought occurent in the

705 southern Africa and that precipitation is the main driver of drought in the region. The variations in the characterization of hydrological processes in the models are also a source of uncertainty 
because they reinforce the bifurcation in rounoff outputs which has cascading effects on biospheric changes, evapotranspiration among others (Murray et al., 2012; Stewart et al., 2004). Also see Fig. $\mathrm{S} 4$ for correlations of the model ensemble median at different timescales. Another reason for the biases in the simulations may be to the design of the DGVM experimental set-up, which include the flux deviation between simulations without and with (Murray et al., 2012).

\section{$5 \quad$ Summary and conclusions}

Southern African vegetation is continually affected by drought. In this study, we estimated the spatiotemporal characteristics of meteorological drought in southern Africa using the Standardized Precipitation Evapotranspiration Index (SPEI) over a 30-year period (1982 - 2011). The severity and drought impacts on vegetation production were examined at various drought time-scales (1to 24-month timescales) by correlating drought index (SPEI) with GIMMS LAI at different timescales. We found that the LAI responds strongly $(r=0.6)$ to drought over the central and south eastern parts of the region, with weaker impacts $(r<0.4)$ over parts of Madagascar and Angola, mostly at a shorter time period (3-, 6-month timescale). For seasonal responses, semi-desert biome showed the strongest response $(\mathrm{r}=0.95)$ to drought at 6-month timescale in the MAM season while the tropical forest biome shows the weakest response $(r=0.35)$ at 6 -month timescale in the DJF season

We assessed the relationship between the NDVI and LAI by computing a grid cell correlation of NDVI and LAI, and also examined how well state of the art dynamic global vegetation models (DGVMs) simulate LAI and its response to drought. The DGVM multi-model ensemble mostly overestimated the spatial and seasonal distribution of LAI response to drought in most parts of the region. The results also show that:

- The relationship between the NDVI and LAI is linear thus implying that the vegetation index is connected to the changes in phenology of plant, reflectance and the angle of zenith variations from the surface cover class.

- The model ensemble shows biases in the correlation and timescale of LAI response to drought.

- The model ensemble overestimates observation on the seasonal distribution of vegetation - drought correlations across the different biomes.

- There is a stronger LAI response to drought in dry years than in wet years (for instance, in the year 1983 which was a dry year, $r>0.84$ over Namibia and northeastern parts of South African but $r<0.70$ in 2000, a wet year in same region); and a variability in the distribution patterns of global and regional response across biomes.

The present study has shown how the LAI responds to drought across the different southern African biomes. Given the present spatial coverage of space monitoring of vegetation in the region, the methods used in the study may be extended towards monitoring and characterizing the impacts 
of droughts on land cover change, as this may permit real-time monitoring of extreme events on terrestrial vegetation (Yin et al., 2020; Moore et al., 2018). The findings of this study (e.g. timescales of LAI response to drought) could also be used for the development of drought early warning systems in agriculture and forestry sectors. This will assist in the mitigation of direct and indirect costs associated with vegetation production.

755 Furthermore, this study has applied eleven DGVMs to study how well DGVMs can reproduce the response of LAI in southern African vegetation to drought. While this study may have provided an insight into the capability of DGVMs to simulate vegetation response to drought. However, the results of the study can however be improved in some ways. For example, we applied eleven models from the TRENDY DGVMs. For future studies, the number of models should be increased,

760 perhaps from other model intercomparison experiments, because using more models might reduce the level of uncertainty and biases in their simulation of drought response by vegetation. The limitation of the DGVMs can be addressed optimizing the models so that their capability in reproducing vegetation indexes is enhanced. In addition, there is a need to improve mechanistic relationships in the models, which could be achieved by enhancing the model approximations which had been done to achieve computational efficiencies (Transtrum, et al., 2016). Furthermore, simple phenomenological model could be developed from the complex model. These simple models would use correlations among observations, unlike mechanistic relationships which exploit causative individual constituent and suffer over-fitting problems (Transtrum, et al., 2016). Lastly, there may be need for hybridizing machine learning and mechanistic models (Fayyad et al., 1996;

770 Mitchell, 1997) to simulate vegetation parameters. This is because machine learning models have shown certain advantage in the prediction of outcomes of complex mechanisms by using databases of inputs and outputs for a given task (Fayyad et al., 1996; Mitchell, 1997).

Data availability. Sources of data used in this work are provided in Section 2.1 and comprise CRU, CRUJRA, NDVI3g and Trendy DGVMs.

Author contributions. S.L. was responsible for conceptualization, developing the initial content of the manuscript, including literature search, data analysis and writing of the manuscript. S.S. and D.L. provided model outputs, and guided on data analysis. J.N., H.W.W., P.F, H.T. and B.H provided guidance in terms of the article structure and finalization of the manuscript.

Competing interests. Authors declare no competing of interest.

Acknowledgements. The work was supported by the South African National Research Foundation (NRF). 


\section{References}

Allen, C.D., Macalady, A.K., Chenchouni, H., Bachelet, D., McDowell, N.; Vennetier, M., and Gonzalez, P.: A global overview of drought and heat-induced tree mortality reveals emerging climate change risks for forests, For. Ecol. Manag., 259, 660-684, https://doi.org/10.1016/j.foreco.2009.09.001, 2010.

Ahlström, A., Raupach, MR., Schurgers, G., Smith, B., Arneth, A., Jung, M., Reichstein, M., Canadell, JG., Friedlingstein, P., Jain, AK., Kato, E., Poulter, B., Sitch, S., Stocker, BD., Viovy, N., Wang, YP., Wiltshire, A., Zaehle, S., andZeng, N.: The dominant role of semiarid ecosystems in the trend and variability of the land CO2 sink, Science, 348, 895-899, https://doi.org/10.1126/science.aaa1668, 2015.

Andela, N., Liu, YY., van Dijk, A. I. J. M., de Jeu, R. A. M., and McVicar, T. R.: Global changes in dryland vegetation dynamics (1988-2008) assessed by satellite remote sensing: Comparing a new passive microwave vegetation density record with reflective greenness data, Biogeosciences 10, 6657-6676, doi:10.5194/bg-10-6657-2013, 2013.

Anyamba, A., Justice, CO., Tucker, CJ., and Mahoney, R.: Seasonal to interannual variability of Vegetation and fires at SAFARI 2000 sites inferred from advanced very high resolution Radiometer time series data, Journal of Geophysical Research, vol 10 no D13, https://doi.org/10.1029/2002JD002464, 2003.

Beguería, S., Vicente-Serrano, SM., Reig, F., and Latorre, B.: Standardized precipitation evapotranspiration index (SPEI) revisited: parameter fitting, evapotranspiration models, tools, datasets and drought monitoring. International Journal of Climatology 34(10), 30013023, https://doi.org/10.1002/joc.3887, 2014.

Bonan, G. B., Oleson, KW., Vertenstein, M., Lewis, S., Zeng, X., Dai, Y., Dickinson, DE., and Yang, Z,: The land surface climatology of the NCAR land surface model coupled to the NCAR community climate model, Journal of Climate, 11, 1307 - 1327, https://doi.org/10.1175/1520-0442, 2002.

Chapotin, SM., Razanameharizaka, JH., and Holbrook, NM,: Water relations of baobab trees (Adansonia spp L.) during the rainy season. Does stem water buffer daily water deficit. Plant and Cell Environment 29, 1021-1032. doi. 10.1111-3040.2005.01456.x, 2006.

Cai, W., Borlace, S., Lengaigne, M., van Rensch, P., Collins, M., Vecchi, G., Timmermann, A., Santoso, A., McPhaden, MJ., Wu, M., England, L., H., Wang, G., Guilyardi, E., Jin, F.F: Increasing frequency of extreme El Nino events due to greenhouse warming. Nat. Clim. Change 4, 111-116, doi:10.1038/nclimate2100, 2014.

Clark, D. B., Mercado, L. M., Sitch, S., Jones, C. D., Gedney, N., Best, M. J., Pryor, M., Rooney, G. G., Essery, R. L. H., Blyth, E., Boucher, O., Harding, R. J., Huntingford, C., and Cox, P. M.: The Joint UK Land Environment Simulator (JULES), model description - Part 2: Carbon fluxes and vegetation dynamics, Geosci. Model Dev., 4, 701-722, https://doi.org/10.5194/gmd-4- 701-2011, 2011.

830 Cohen, W. B., Maiersperger, T. K., Gower, S. T. and Turner, D. P.: An improved strategy for regression of biophysical variables and Landsat ETM+ data., Remote Sensing of Environment, 84: 561-571, https://doi.org/10.1016/S0034-4257(02)00173-6, 2003

Corlett, RT.: The Impacts of Droughts in Tropical Forests. Trends Plant Sci 21(7) 584593, https://doi.org/10.1016/j.tplants.2016.02.003, 2016. 
Dai, A.: Increasing drought under global warming in observations and models, Nat. Clim. Change 3, 52-58, doi:10.1038/nclimate1633, 2013.

Din, M., Zheng, W., Rashid, M., Wang, S., and Shi, Z.: Evaluating Hyperspectral Vegetation Indices for Leaf Area Index Estimation of Oryza sativa L. at Diverse Phenological Stages, Front. Plant Sci., 8, doi/10.3389/fpls.2017.00820, 2017

Donohue, R. J., McVicar, T. R., and Roderick, M. L.: Climate-related trends in Australian vegetation cover as inferred from satellite observations, 1981-2006. Glob. Change Biol. 15, 1025-1039, doi:10.1111/j.1365-2486.2008.01746.x, 2009.

Dupont, LM.: Late Pliocene vegetation and Climate and Namibia (Southern Africa) derived From Palynology of ODP site 1082. Geochemistry, Geophysics and Geosystems, An AGU Journal. Vol 7 issue 5. doi: 10.1029.2005/gc001208, 2006.

Earth Summit, United Nation Conference on Environment and Development.: https://sustainabledevelopment.un.org/outcomedocuments/agenda21, 1992.

El-Vilaly, M.A.S., Didan, K., Marsh, S.E., van Leeuwen, W.J., Crimmins, M.A., and Munoz, A.B.: Vegetation productivity responses to drought on tribal lands in the four corners region of the Southwest USA, Front. Earth Sci., 12, 37-51, doi. https://doi.org/10.1007/s11707-017-0646-z, 2017.

Fan, L., Gao, Y., Brück, H., and Bernhofer, Ch.: Investigating the relationship between NDVI and LAI in semi-arid grassland in Inner Mongolia using in-situ measurements Theoretical and Applied Climatology, 10.1007/s00704-007-0369-2, 2008.

Fayyad, U., Piatetsky-Shapiro, G., Smyth, P. (Eds): From data mining to knowledge discovery Databases. AI Magazine 17, 37. 1996.

Fensholt, R., Langanke, T., Rasmussen, K., Reenberg, A., Prince, S. D.,Tucker, C., Scholes, R. J., Le, Q. B., Bondeau, A., Eastman, R., Epstein, H., Gaughan, A. E., Hellden, U., Mbow, C., Olsson, L., Paruelo, J., Schweitzer, C., Seaquist, J., and Wessels. K.: Greenness in semi-arid areas across the globe 1981-2007-an Earth Observing Satellite based analysis of trends and drivers, Remote Sens. Environ. 121, 144-158. doi:10.1016/j.rse.2012.01.017, 2012.

FAO. 2000b (Eds). FAO/ESAF Handbook for Defining and Setting up a Food Security Information and Early Warning System (FSIEWS). Rome

Fuller, DO., and Prince, SD.: Rainfall and foliar dynamics in tropical southern Africa: Potential impacts of global climatic change on savanna vegetation, Clim Change 33,69-96. 10.1007/BF00140514, 1996.

Gielen, B., De Boeck, H., Lemmens, CMHM., Valcke, R., Nijs, I., and Ceulemans, R.: Grassland species will not necessarily benefit from future elevated air temperatures: a chlorophyll fluorescence approach to study autumn physiology. Physiol Plant 125:52-63, doi:10.1111/j.1399-3054.2005.00539.x, 2005.

Gitelson, A. A.: Wide dynamic range vegetation index for remote quantification of biophysical characteristics of vegetation, Journal of Plant Physiology, vol. 161, no. 2, pp. 165-173, https://doi.org/10.1078/0176-1617-01176, 2004.

Gitelson, A.A., Viña, A., Ciganda, V., Rundquist, D.C., and Arkebauer, T.J.: Remote estimation of canopy chlorophyll content in crops Geophysical Research Letters, 32, p. L08403, 10.1029/2005GL022688, 2005.

Glantz, M.H., Betsill, M. and Crandall, K.: Food security in southern Africa. Assessing the 
use and value of ENSO information. National Center for Atmospheric Research, Boulder, CO, USA, 1997.

Goll, D. S., Vuichard, N., Maignan, F., Jornet-Puig, A., Sardans, J., Violette, A., Peng, S., Sun, Y., Kvakic, M., Guimberteau, M., Guenet, B., Zaehle, S., Penuelas, J., Janssens, I., and Ciais, P.: A representation of the phosphorus cycle for ORCHIDEE, Geosci. Model Dev., 10, 3745-3770, https://doi.org/10.5194/gmd-10-3745-2017, 2017.

Hao, Z., and AghaKouchak, A.: Multivariate standardized drought index: a parametric multi-index model, Advances in Water Resources, 57, 12-18., https://doi.org/10.1016/j.advwatres.2013.03.009 2013

Haverd, V., Smith, B., Nieradzik, L., Briggs, P. R., Woodgate, W., Trudinger, C. M., Canadell, J. G., and Cuntz, M.: A new version of the CABLE land surface model (Subversion revision r4601) incorporating land use and land cover change, woody vegetation demography, and a novel optimisation-based approach to plant coordination of photosynthesis, Geosci. Model Dev., 11, 2995- 3026, https://doi.org/10.5194/gmd-112995-2018, 2018.

Harris, I., Jones, PD., Osborn, TJ., and Lister, DH.: Updated high-resolution grids of monthly climatic observations - the CRU TS3.10 Dataset. Int. J. Climatol. 34(3), 623-642, doi: 10.1002/joc.3711, 2014.

Hoffman, MT., Carrick, PJ., and West, AG.: Drought, climate change and vegetation response in the succulent karoo, South Africa. South African Journal of Science S.Afr. j. sci. vol05:1-2, S. Afr. j. sci. vol.105 n.1-2 Pretoria Jan./Feb., 2009

Homdee, T., Pongput, K., and Kanae, S.: A comparative performance analysis of three standardized climatic drought indices in the Chi River basin, Thailand. Agriculture and Natural Resources, 50(3), 211-219. https://doi.org/10.1016/j.anres.2016.02.002,_2016.

Hou, W., Gao, J., Wu, S., Dai, E.: Interannual Variations in Growing-Season NDVI and Its Correlation with Climate Variables in the Southwestern Karst Region of China. Remote Sens., 7, 11105-11124, https://doi.org/10.3390/rs70911105, 2015.

Ji, L., and Peters, AJ.: Performance evaluation of spectral vegetation indices using a statistical sensitivity function. Remote Sensing of Environment 106, 59-65,

910 https://doi.org/10.1016/j.rse.2006.07.010 2007.

Junges, A. H., Fontana, D., Anzanello, R. and Bremm, C.: Normalized difference vegetation index obtained by ground-based remote sensing to characterize vine cycle in Rio Grande do Sul, Brazil. Ciência e Agrotecnologia, 41, 543-553. https://doi.org/10.1590/1413-70542017415049016,_2017.

Khosravi, H., Haydari, E., Shekoohizadegan, S., and Zareie, S.: Assessment the effect of drought on vegetation in desert area using landsat data Egypt. J. Remote Sens. Space Sci., 2007 (20), pp. S3-S12 ISSN 1110-9823, https://doi.org/10.1016/j.ejrs.2016.11.007, 2017.

Kato, E., Kinoshita, T., Ito, A., Kawamiya, M., and Yamagata, Y.: Evaluation of spatially explicit emission scenario of landuse change and biomass burning using a process-based biogeochemical model, Journal of Land Use Science, 8, 104-122, https://doi.org/10.1080/1747423X.2011.628705, 2013.

Kwon, M., Kwon, H.H., Han, D.: Spatio-temporal drought patterns of multiple drought indices based on precipitation and soil moisture: a case study in South Korea Int. J. Climatol., 1-19 (2019), 10.1002/joc.6094, 2019.

Lake PS (eds) (2011). Drought and Aquatic Ecosystems: Effects and Response 
Lange, C. B., Berger, W. H. , Lin, H.-L., Wefer, G. and Shipboard Scientific Party Leg 175.: The early Matuyama diatom maximum off SW Africa, Benguela current system (ODP Leg 175), Mar. Geol., 161, 93-114, https://doi.org/10.1016/S0025-3227(99)00081X, 1999

Lawal S., Lennard C., jack C. Wolski P., Hewitsin B., and Abiodun B.: The observed and model-simulated response of southern African vegetation to drought. https://doi.org/10.1016/j.agrformet.2019.107698,_2019.

Lawal S., Lennard C and Hewitson B.: Response of southern African vegetation to climate change at 1.5 and 2.0 degrees global warming above the pre-industrial level. Climate Services 16C 100134, 2019.

Le Quéré, C., Peters, G. P., Andres, R. J., Andrew, R. M., Boden, T. A., Ciais, P., Friedlingstein, P., Houghton, R. A., Marland, G., Moriarty, R., Sitch, S., Tans, P., Arneth, A., Arvanitis, A., Bakker, D. C. E., Bopp, L., Canadell, J. G., Chini, L. P., Doney, S. C., Harper, A., Harris, I., House, J. I., Jain, A. K., Jones, S. D., Kato, E., Keeling, R. F., Klein Goldewijk, K., Körtzinger, A., Koven, C., Lefèvre, N., Maignan, F., Omar, A., Ono, T., Park, G.-H., Pfeil, B., Poulter, B., Raupach, M. R., Regnier, P., Rödenbeck, C., Saito, S., Schwinger, J., Segschneider, J., Stocker, B. D., Takahashi, T., Tilbrook, B., van Heuven, S., Viovy, N., Wanninkhof, R., Wiltshire, A., and Zaehle, S.: Global carbon budget 2013, Earth Syst. Sci. Data, 6, 235-263, https://doi.org/10.5194/essd-6-235-2014, 2014.

Lienert, S., and Joos, F.: A Bayesian ensemble data assimilation to constrain model parameters and land-use carbon emissions, Biogeosciences, 15, 2909-2930, https://doi.org/10.5194/bg-15- 2909-2018, 2018.

Lu, E., Luo, Y., Zhang, R., Wu, Q., and Liu, L.: Regional atmospheric anomalies responsible for the 2009-2010 severe drought in China, J. Geophys. Res., 116 (D21), https://doi.org/10.1029/2011JD015706, 2011.

Lu, E., Cai, W., Jiang, Z., Zhang, Q., Zhang, C., Higgins, R.W., and Halpert, M.S.: The day-today monitoring of the 2011 severe drought in China, Clim. Dynam, https://doi.org/10.1007/s00382-013-1987-2, 2014.

Mao, J., and Yan, B.: Global Monthly Mean Leaf Area Index Climatology, 1981-2015. ORNL DAAC, Oak Ridge, Tennessee, USA. https://doi.org/10.3334/ORNLDAAC/1653, 2019.

Masih, I., Uhlenbrook, S., Maskey, S., and Smakhtin, V.: Stream-flow trends and climate linkages in the Zagros Mountain, Iran. Clim. Change, 104, 317-338, doi:10.1007/s10584009-9793-x, 201, 2014.

Mauritsen, T., Bader, J., Becker, T., Behrens, J., Bittner, M., Brokopf, R., Brovkin, V., Claussen, M., Crueger, T., Esch, M., Fast, I., Fiedler, S., Popke, D., Gayler, V., Giorgetta, M., Goll, D., Haak, H., Hagemann, S., Hedemann, C., Hohenegger, C., Ilyina, T., Jahns, T., Jimenez Cuesta de la Otero, D., Jungclaus, J., Kleinen, T., Kloster, S., Kracher, D., Kinne, S., Kleberg, D., Lasslop, G., Kornblueh, L., Marotzke, J., Matei, D., Meraner, K., Mikolajewicz, U., Modali, K., Möbis, B., Müller, W., Nabel, J. E. M. S., Nam, C., Notz, D., Nyawira, S., Paulsen, H., Peters, K., Pincus, R., Pohlmann, H., Pongratz, J., Popp, M., Raddatz, T., Rast, S., Redler, R., Reick, C., Rohrschneider, T., Schemann, V., Schmidt, H., Schnur, R., Schulzweida, U., Six, K., Stein, L., Stemmler, I., Stevens, B., von Storch, J., Tian, F., Voigt, A., de Vrese, P., Wieners, K.-H., Wilkenskjeld, S., Roeckner, E., and Winkler, A Developments in the MPI-M Earth System Model version 1.2 (MPI-ESM1.2) 
and its response to increasing CO2, J. Adv. Model. Earth Sy., https://doi.org/10.1029/2018MS001400, 2018.

McKee, T. B., Doesken, N. J. and Kleist, J.: The relationship of drought frequency and duration to time scales. Proc. Eight Conf. on Applied Climatology. Anaheim, CA, Amer. Meteor. Soc. 179-184, 1993

Melillo, J.: Climate change, risky business, and a call to action for ecologists. Ecosystem Health and Sustainability 1(1), https://doi.org/10.1890/EHS14-0016.1, 2015.

Melton, J. R., and Arora, V. K.: Competition between plant functional types in the Canadian Terrestrial Ecosystem Model (CTEM) v. 2.0, Geosci. Model Dev., 9, 323-361, https://doi.org/10.5194/gmd-9-323-2016, 2016.

Mitchell TM. 1997Machine learning. Boston, MA: McGraw-Hill Series in Computer Science.

Mitchell, TD., and Jones, PD.: An improved method of constructing a database of monthly climate observations and associated high- resolution grids. Int. J. Climatol. 25: 693-712, https://doi.org/10.1002/joc.1181, 2005.

Moore, B., Crowell, S. M. R., Rayner, P. J., Kumer, J., O'Dell, C. W., O'Brien, D., Utembe, S., Polonsky, I., Schimel, D., and Lemen, J.: The potential of the geostationary carbon cycle observatory (GeoCarb) to provide multi-scale constraints on the carbon cycle in the Americas. Frontiers in Environmental Science, 6, 109, https://doi.org/10.3389/fenvs.2018.00109, 2018.

Mukherjee, N., Zabala, A., Huge, J., Nyumba, T. O., Esmail, B. A., and Sutherland, W. J.: Comparison of techniques for eliciting views and judgements in decisionmaking. Methods in Ecology and Evolution, 9, 54- 63, https://doi.org/10.1111/2041210X.12940, 2017.

Murray, SJ., Foster, PN., and Prentice, IC.: Evaluation of global continental hydrology as simulated by the Land-surface Processes and eXchanges Dynamic Global Vegetation Model. Hydrology and Earth System Sciences 15: 91-105, https://doi.org/10.5194/hess15-91-2011, 2011.

Myoung, B., Choi, Y.-S., Hong, S., and Park S. K.: Inter- and intra-annual variability of vegetation in the northern hemisphere and its association with precursory meteorological factors, Global Biogeochem. Cycles, 27, 31- 42, doi:10.1002/gbc.20017, 2013.

Naik, M., and Abiodun, BJ.: Potential impacts of forestation on future climate change in Southern Africa. International Journal of Climatology. doi:10.1002/joc.4652, 2016.

Naumann, G., Alfieri, L., Wyser, K., Mentaschi, L., Betts, R.A., Carrao, H., Spinoni, J., Vogt, J., Feyen, L.: Global changes in drought conditions under different levels of warming. Geophys. Res. Lett., 45, 3285-3296., https://doi.org/10.1002/2017GL076521, 2018.

New, M.: Are semi-arid regions climate change hot-spots? Evidence from Southern Africa, African Climate and Development Initiative (ACDI) blog, 2015.

Oleson, K. W., Dai, Y., Bonan, G., Bosilovich, M., Dickinson, R., Dirmeyer, P., Hoffman, F., Houser, P., Levis, S., Niu, G.-Y., Thornton, P., Vertenstein, M., Yang, Z.-L. and Zeng, X.: Technical description of the Community Land Model (CLM). NCAR Tech. Note NCAR/TN-461+STR, 174 pp, 2004.

Oleson, K., Lawrence, D., Bonan, G., Drewniak, B., Huang, M., Koven, C., Levis, S., Li, F., Riley, W., Subin, Z., Swenson, S., Thornton, P., Bozbiyik, A., Fisher, R., Heald, C., Kluzek, E., Lamarque, J., Lawrence, P., Leung, L., Lipscomb, W., Muszala, S., Ricciuto, D., Sacks, W., Tang, J., and Yang, Z.: Technical Description of version 4.5 of the 
1020

Community Land Model (CLM), NCAR, available at: http://www.cesm.ucar.edu/models/cesm1.2/ clm/CLM45_Tech_Note.pdf, 2013.

Palmer WC.: Keeping track of crop moisture conditions, nationwide: the new Crop Moisture Index. Weatherwise 21:156-161, https://doi.org/10.1080/00431672.1968.9932814, 1968.

Pinzon, J. E. and Tucker, C. J.: A Non-Stationary 1981-2012 AVHRR NDVI3g Time Series, Remote Sensing, 6, 6929-6960, https://doi.org/10.3390/rs6086929, 2014.

Potithep, S., Nasahara, N., Muraoka, H., Nagai, S. and Suzuki, R.: What is the actual relationship between LAI and VI in a deciduous broadleaf forest. International Archives of the Photogrammetry, Remote Sensing and Spatial Information Science 38, 609-614, 2010.

Poulter, B., Frank, D., Ciais, P., Myneni, R. B., Andela, N., Broquet, G. J. B, Canadell, J. G., Chevallier, F., Liu, Y. Y., Running, S. W., Sitch, S., and van der Werf, G. R.: Contribution of semi-arid ecosystems to interannual variability of the global carbon cycle. Nature 509, 600-603, doi:10.1038/nature13376pmid:2484788, 2014.

Potter, C.S., and Klooster, S.A.: Global model estimates of carbon and nitrogen storage in litter and soil pools: response to change in vegetation quality and biomass allocation. Tellus, 49B, 1, https://doi.org/10.3402/tellusb.v49i1.15947, 1997.

Potter, CS, and Klooster, SA.: Dynamic global vegetation modelling for prediction of plant types and biogenic trace gas fluxes. Global Ecol Biogeogr 8:473-488, https://doi.org/10.1046/j.1365-2699.1999.00152.x, 1998

Running, S. W., \& Coughlan, J. C.: A general model of forest ecosystem processes for regional applications. Ecological Modelling, 42, $124-154$., https://doi.org/10.1016/0304-3800(88)90112-3, 1988.

Santin-Janin, H., Garel, M., Chapuis, J.-L., and Pontier, D.: Assessing the performance of NDVI as a proxy for plant biomass using non-linear models: a case study on the Kerguelen archipelago Polar Biology, 32 (2009), pp. 861-871, https://doi.org/10.1007/s00300-0090586-5, 2009.

Schwinning, S., Starr, B. I., and Ehleringer, J. R., Summer and winter drought in a cold desert ecosystem (Colorado Plateau) part II: effects on plant carbon assimilation and growth. Journal of Arid Environments 61:61-78., https://doi.org/10.1016/j.jaridenv.2004.07.013, 2005.

Sinclair, REA., and Beyers, RL.: African Biomes. Ecology. doi.10.10/OBO978199830060., 2015.

1050 Sellers, P. J., Randall, D. A., Collatz, G. J., Berry, J. A., Field, C. B., Dazlich, D. A., Zhang, C., and Collelo, GD., and Bounuoa, L.: A revised land surface parameterization (SIB2) for Atmospheric GCMs: Part I. Model formulation. Journal of Climate, 9, 676 - 705., https://doi.org/10.1175/1520-0442, 1996.

Scott, R.: Using watershed water balance to evaluate the accuracy of eddy covariance evaporation measurements for three semiarid ecosystems, Agr. For. Meteorol., 150, 219 225, doi:10.1016/j.agrformet. 2009.11.002., 2010.

Sitch, S., Huntingford, C., Gedney, N., Levy, P.E., Lomas, M., Piao, S.L., Betts, R.,Ciais, P., Cox, P., Friedlingstein, P., Jones, CD., Prentice, IC., and Woodward, FI.: Evaluation of the terrestrial carbon cycle, future plant geography and climate-carbon cycle feedbacks using five Dynamic Global Vegetation Models (DGVMs). Global Change Biol., 14, 2015-2039, https://doi.org/10.1111/j.1365-2486.2008.01626.x, .2008.

Stagge, J. H., Tallaksen, L.M., Gudmundsson, L., van Looon, A.F. and Stahl, K.: PanEuropean comparison of candidate distributions for climatological drought indices (SPI 

363, 2014.

Stewart, IT., Cayan, DR., Dettinger, MD.: Changes in snowmelt runoff timing in western North America under a 'business as usual' climate change scenario. Climatic Change 62(13): 217-232., https://doi.org/10.1023/B:CLIM.0000013702.22656.e8, 2004.

Sultan, B., and Gaetani, M.: Agriculture in West Africa in the twenty-first century: Climate change and impacts scenarios, and potential for adaptation. Frontiers in Plant Science, 7, 1- 20, doi: 10.3389/fpls.2016.01262, 2016

Tian, F., Brandt, M., Liu, Y. Y., Rasmussen, K., and Fensholt, R.: Mapping gains and losses in woody vegetation across global tropical drylands. Global Change Biology, 23(4), 1748-1760. https://doi.org/10.1111/gcb.13464, 2017.

Transtrum, MK., Qiu, P.: Bridging mechanistic and phenomenological models of complex biological systems. PLoS Comput Biol 12(5):e1004, 915, https://doi.org/10.1371/journal.pcbi.1004915, 2016.

Trenberth, K. E., A. Dai, G. van der Schrier, P. D. Jones, J. Barichivich, K. R. Briffa, and J. Sheffield.: Global warming and changes in drought, Nat. Clim. Change, 4(1), 17-22., https://doi.org/10.1038/nclimate2067, 2014.

Teuling, AJ., vanLoon A., Seneviratne S., Lehner, M., Aubinet M., Heinesch B., Bernhofer, C., Grunwald, T., Prasse, H., and Spank, U.: Spank Evapotranspiration amplifies European summer drought Geophys. Res. Lett., 40 (10), pp. 2071-2075, https://doi.org/10.1002/grl.50495, 2013.

Tian, H. Q., Chen, G. S., Lu, C. Q., Xu, X. F., Hayes, D. J., Ren, W., Pan, S. F., Huntzinger, D. N., and Wofsy, S. C.: North American terrestrial CO2 uptake largely offset by $\mathrm{CH} 4$ and $\mathrm{N} 2 \mathrm{O}$ emissions: toward a full accounting of the greenhouse gas budget, Climatic Change, 129, 413-426, https://doi.org/10.1007/s10584- 014-1072-9, 2015.

Ujeneza, E., and Abiodun, BJ., Drought regimes in Southern Africa and how well GCMs simulate them? Clim Dyn, 44 (5), 1595-1609, 10.1007/s00382-014-2325-z, 2015.

United Nations Environmental Protection - UNEP (2008). Atlas of changing environment. Biomes of Africa. Nairobi, Kenya: UNEP.

Vicente-Serrano, SM., Beguería, S., López-Moreno, JI., Angulo, M. El Kenawy, A.: A new global $0.5^{\circ}$ gridded dataset (1901-2006) of a multiscalar drought index: comparison with current drought index datasets based on the Palmer Drought Severity Index. Journal of Hydrometeorology 11: 1033-1043, https://doi.org/10.1175/2010JHM1224.1, 2010.

Vicente-Serrano, S. M, Bengueria, S., and Lopez-Moreno, J.:Comment on "Characteristics and trends in various forms of the Palmer Drought Severity Index (PDSI) during 1900-2008”, by Aiguo Dai.J. Geophys. Res.,116,D19112, doi:10.1029/2011JD016410, 2011.

Vicente-Serrnao, SM., Gouvelia, C., Camarero, J.J, Begueria, S., Trigo, R., Lopez-Moreno, JI., Azorin-Molina, A., Pasho, E., Lorenzo-Lacruz., J, Revuelto, J., Moran-Tejeda, E., and Sanchez-Lorezo, A.: Response of vegetation to drought time-scales across global land biomes. PNAS Vol 110 1. www.pnas.org/cgi/doi/10.1073/pnas.1207068110, 2012.

Vicente-Serrano, Sergio M. and National Center for Atmospheric Research Staff (Eds).:

"The Climate Data Guide: Standardized Precipitation Evapotranspiration Index (SPEI)." Retrieved from https://climatedataguide.ucar.edu/climate-data/standardized-precipitationevapotranspiration-index-spei., 2015.

Wang, Q., Tenhunen, J., Dinh, NQ., Reichstein, M., Vesala, T., and Keronen, P.: Similarities in 
ground- and satellite-based ndvi time series and their relationship to physiological activity of a Scots pine forest in Finland. Remote Sensing of Environment 93, 225-237., 10.1016/j.rse.2004.07.006, 2004.

Wang A, Li, KY., and Lettenmailer DP.: Integration of the Variable Infiltration Capacity Model Soil hydrology scheme into the Community Land Model. Climate and Dynamics, https://doi.org/10.1029/2007JD009246, 2008.

Wang, X., Piao, S., Ciais, P., Friedlingstein, P., Myneni, R.B., Cox, P., Heimann, M., Miller, J., Peng, S., Wang, T., Yang, H., and Chen, A.: A two-fold increase of carbon cycle sensitivity to tropical temperature variations. Nature 506, 212215 (2014). doi:10.1038/nature12915 pmid:24463514, 2014.

Ward, J. D., Seely, M. K., and Lancaster, N.: On the antiquity of the Namib, S. Afr. J. Sci., 79, 175-183, 1983.

Wilhite, D.A., and Glantz, M.H.: Understanding the drought phenomenon: the role of definitions, Water Int., 10 (3), pp. 111-120, https://doi.org/10.1080/02508068508686328, 1985.

Woodward, FI., and Lomas, MR.: Vegetation-dynamics - simulating responses to climate Change. Biological Reviews 79, 643 - 670, https://doi.org/10.1017/S1464793103006419, 2004.

WRI (World Resources Institute). 2000. World resources 2000-2001. People and ecosystems:

Xu, K., Yang, D., Yang, H., Li, Z., Qin, Y., Shen, Y.: Spatio-temporal variation of drought in China during 1961-2012: a climatic perspective J. Hydrol., 526, pp. 253264, 10.1016/j.jhydrol.2014.09.047, 2015.

Xue, J., and Su, B.: Significant remote sensing vegetation indices: a review of developments and applications, J. Sens., p. 17, https://doi.org/10.1155/2017/1353691, 2017.

Yang, Y, J., Fang, J., W, Ma and Wang, W.: Relationship between variability in aboveground Net primary production in global grasslands. Geophy Res Lett Vol 35, 123710, doi:10.1029/2008GLO35408, 2008.

Yin, Y., Byrne, B., Liu, J., Wennberg, P., Davis, K. J., Magney, T., et al.: Cropland carbon uptake delayed and reduced by 2019 Midwest floods. AGU Advances, 1, e2019AV000140. https:// doi.org/10.1029/2019AV000140., 2020.

Zaehle, S., Ciais, P., Friend, A. D., and Prieur, V.: Carbon benefits of anthropogenic reactive nitrogen offset by nitrous oxide emissions, Na. Geosci., 4, 601-605, https://doi.org/10.1038/NGEO1207, 2011.

Zeppel MJB, Wilk JV and Lewis JD.: Impacts of extreme precipitation on plants. Biogeosciences, 11, 3083 - 3093. doi. 10.5194/bg-11 3083-2004, 2014.

1145 Zhang, L., Xiao, J., Li, J., Wang, K., Lei, L., and Guo, H.: The 2010 spring drought reduced primary productivity in southwestern China, Environ. Res. Lett., 7 (4), p. 045706, 10.1088/1748-9326/7/4/045706, 2012

Zhao, C., Deng, X., Yuan, Y., Yan, H., and Liang, H.: Prediction of drought risk based on the WRF model in yunnan province of China Adv. Meteorol., pp. 1-9, https://doi.org/10.1155/2013/295856, 2013. 